\title{
INSTAGRAM Y LA ESPECTACULARIZACIÓN DE LAS CRISIS POLÍTICAS. LAS 5W DE LA IMAGEN DIGITAL EN EL PROCESO INDEPENDENTISTA DE CATALUÑA
}

\author{
Instagram and the spectacularization of political \\ crises. The $5 \mathrm{~W}$ of the digital image in the \\ independence process in Catalonia
}

Pablo López-Rabadán y Hugo Doménech-Fabregat

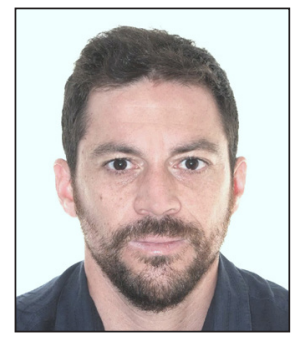

Pablo López-Rabadán es profesor contratado doctor en el Departamento de Ciencias de la Comunicación de la Universitat Jaume I (España). Es licenciado por la Universitat Autònoma de Barcelona y doctor por la Universidad Rey Juan Carlos. Ha sido investigador visitante en las universidades de Westminster, Valparaíso y en el Emerson College de Boston, entre otras. Trabaja sobre la transformación digital del periodismo especializado y el impacto de las redes sociales en la comunicación política. En los últimos años ha publicado en revistas como American behavioral scientist, Journalism, o Estudios sobre el mensaje periodístico, entre otras.

https://orcid.org/0000-0002-4828-4933

rabadan@uji.es

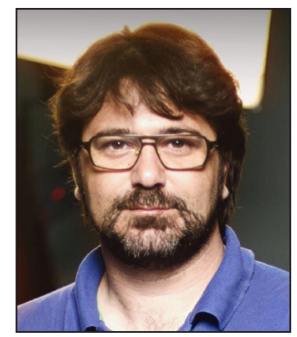

Hugo Doménech-Fabregat es profesor contratado doctor en el Departamento de Ciencias de la Comunicación de la Universidad Jaume I (España). Licenciado por la Universidad Pontificia de Salamanca y doctor por la Universidad Jaume I. Es vicedecano del grado en Periodismo en esa misma universidad. Sus líneas de investigación se centran en fotoperiodismo y los géneros periodísticos en su adaptación al entorno digital. Ha codirigido el largometraje documental "La sombra del iceberg. Autopsia a la mítica fotografía de Robert Capa" (2007), premiado en diversos festivales nacionales e internacionales.

https://orcid.org/0000-0002-1247-9587

hdomenec@uji.es

Universitat Jaume I de Castelló Facultat de Ciències Humanes i Socials Departament de Ciències de la Comunicació Avda. Vicent Sos Baynat, s/n. 12071 Castelló de la Plana, España

\section{Resumen}

Instagram se ha convertido en un importante medio para la producción y distribución de imágenes políticas. Nuestro objetivo es analizar su gestión estratégica en un contexto de crisis política e institucional. A partir de un modelo de análisis de contenido propio, se han revisado nueve categorías temáticas y formales asociadas a la espectacularización de la política durante la fase más intensa del proceso independentista en Cataluña, entre junio de 2017 y abril de 2018. Integran la muestra 188 imágenes publicadas por los 10 principales líderes del mapa político catalán y español, tanto en votos de sus partidos como en seguidores en Instagram. Los resultados muestran un uso político regular caracterizado por una intensa personalización y la orientación hacia temas profesionales. Además se detecta el uso de recursos de base espectacular como la apelación emocional, la hibridación de espacios y la experimentación con filtros expresivos.

\section{Palabras clave}

Comunicación política; Crisis política; Medios sociales; Instagram; Fotografía política; Espectacularización; Personalización; Humanización; Independencia; Cataluña.

\section{Abstract}

Instagram has become an important tool for the production and distribution of political images. Our objective is to analyze its strategic management in a context of political and institutional crisis. Based on our own model of content analysis, nine thematic and formal categories associated with the spectacularization of politics during the most intense phase of the inde- 
pendence process in Catalonia, between June 2017 and April 2018, have been reviewed. The sample includes 188 images published by the top 10 leaders of the Catalan and Spanish political map, both in votes of their parties and followers Instagram. The results show a regular political use characterized by intense personalization and orientation towards professional issues. In addition, a use of spectacular resources is detected, such as emotional appeal, the hybridization of spaces, and the experimentation with expressive filters.

\section{Keywords}

Political communication; Political crisis; Social media; Instagram; Political photography; Spectacularization; Personalization; Humanization; Independence; Catalonia.

López-Rabadán, Pablo; Doménech-Fabregat, Hugo (2018). "Instagram y la espectacularización de las crisis políticas. Las $5 W$ de la imagen digital en el proceso independentista de Cataluña". El profesional de la información, v. 27, n. 5, pp. 1013-1029.

https://doi.org/10.3145/epi.2018.sep.06

\section{Introducción. Enfoque y objetivos de la investigación}

En los últimos años Instagram se ha configurado como una plataforma muy dinámica para la producción y distribución viral de imágenes políticas. Líderes y partidos han incorporado esta red de intercambio fotográfico a sus equipos de comunicación, y comienza a profesionalizarse su gestión tanto a nivel internacional (Filimonov; Russmann; Svensson, 2016; Lalancette; Raynauld, 2017) como en España (Quevedo-Redondo; Portalés-Oliva, 2017; Marcos-García; Alonso-Muñoz, 2017). Por su naturaleza visual y móvil, Instagram ofrece grandes posibilidades para una comunicación política más natural y espontánea (Selva-Ruiz; Caro-Castaño, 2017).

Este trabajo se aproxima a la gestión de Instagram desde un enfoque concreto: analizar su papel en la espectacularización de la política. Carente de una gran formulación teórica, el estilo comunicativo de Instagram se basa en la utilización de temas y recursos expresivos impactantes en el mensaje político (Montagut; Carrillo, 2017). Su uso se ha popularizado por su capacidad de distribución viral y la posibilidad de incluir mensajes de gran carga espectacular (López-García, 2017). Instagram tiene un gran potencial por su naturaleza multimedia y su facilidad de uso a través del móvil (Quevedo-Redondo; Portalés-Oliva, 2017; Towner; Muñoz, 2017)

Instagram apareció en octubre de 2010 como un híbrido entre el estilo interactivo de redes consolidadas como Facebook y Twitter y el contenido fotográfico de Flickr. Tras años de continua expansión, se ha convertido en la segunda red a nivel mundial, tras Facebook y por delante de Twitter, con más de 800 millones de seguidores (a finales de 2017) y un grado de actividad cercano a los 300 millones de publicaciones diarias (Instagram, 2017; WeAreSocial, 2018). En España, esta expansión ha sido especialmente intensa en los últimos años (34\% anual en 2017) hasta alcanzar los 13 millones de usuarios en 2017. Destaca por sus altos indicadores de actividad (IAMC, 2018) y de frecuencia de uso (IAB, 2018).

Tradicionalmente, las imágenes han sido un recurso estratégico en las campañas electorales por su influencia en la forma en que el público interpreta los mensajes políticos y evalúa a los candidatos (Schill, 2012). Sin embargo, su im- portancia ha aumentado en las últimas décadas por dos factores (Lalancette; Raynauld, 2017):

- el infotainment ha convertido a la televisión en la principal fuente de información política (Jebril; Albaek; De-Vreese, 2013), consolidando la primacía de la imagen y la emotividad en comunicación política (Sartori, 1998);

- la web 2.0 ha dinamizado un uso estratégico por parte de los partidos (López-Rabadán; López-Meri; Doménech-Fabregat, 2016).

En el terreno de las redes sociales su importancia ha sido creciente, desde un papel más complementario en Twitter (López-Meri; Marcos-García; Casero-Ripollés, 2017), hasta convertirse en un contenido central en el desarrollo de estrategias de personalización de candidatos en Instagram (Filimonov; Russmann; Svensson, 2016) o la dinamización en un contexto de campaña permanente en Facebook (Larsson, 2016). En este proceso, los políticos han entendido el potencial de la imagen digital para conectar directamente con los ciudadanos, contrarrestando la acción de medios y adversarios (Stromer-Galley, 2014). Y como resultado, redes como Instagram han construido una cultura visual de la política en la que se mezclan lo informativo y lo personal, lo ideológico y el entretenimiento, con un estilo potencialmente espectacular (Quevedo-Redondo; Portalés-Oliva, 2017).

Instagram se ha convertido en la segunda red social, con más de 800 millones de seguidores (2017), sólo superada por Facebook

Dentro de las consecuencias de la mediatización de la política (Strömbäck, 2008), la espectacularización sobresale como un proceso determinante. Partidos y líderes han tenido que introducir una alta personalización o temas de la vida privada en sus mensajes para lograr una presencia destacada en los medios (Adam; Maier, 2010). Pero la irrupción de las redes sociales ha alterado ese tablero de relaciones en comunicación política (Lilleker; Tenscher; Štětka, 2015; López-García, 2017). En el "sistema híbrido digital”, medios y partidos compiten como canal informativo, se influyen mutuamente y tienden a equilibrar su capacidad de impacto social (Chadwick, 2013). En este proceso, los partidos han 
adoptado una agenda y un estilo comunicativo cada vez más espectacular en su comunicación 2.0 en busca de audiencia y de la movilización de sus seguidores (Bentivegna, 2015; Enli, 2017). En concreto, han optado por adaptar al contexto digital ciertas técnicas narrativas derivadas de la mediatización, como la visualización, simplificación o polarización (Meyen; Thieroff; Strenger, 2014).

Redes sociales como Instagram están construyendo una cultura visual de la política en la que se mezclan lo informativo y lo personal, lo ideológico y el entretenimiento, con un estilo potencialmente espectacular

Para el análisis del uso político de Instagram se ha seleccionado como caso de estudio la crisis independentista en Cataluña. Este tipo de crisis representan un momento clave en comunicación política por varios motivos:

- resultan decisivas en la construcción social del debate público (Casero-Ripollés, 2009);

- articulan dinámicas de máxima actividad comunicativa e interacción entre medios y partidos (Casero-Ripollés, 2008);

- despiertan un gran interés social y consumo informativo entre los ciudadanos (Meilán, 2010; Strömbäck; Djerf-Pierre; Shehata, 2013).

En este sentido, se presentan como un contexto oportuno para estudiar el nivel de espectacularización del mensaje político, sus principales rasgos estilísticos y las estrategias desarrolladas al respecto.

Se trata de un enfoque novedoso ya que hasta el momento la investigación sobre Instagram se ha centrado en procesos electorales (Filimonov; Russmann; Svensson, 2016; Muñoz; Towner, 2017), o sobre el proceso de "celebritización" de la imagen de líderes (Lalancette; Raynauld, 2017). Por su parte, en España encontramos principalmente estudios exploratorios sobre su uso en campaña (Quevedo-Redondo; Portalés-Oliva, 2017; Marcos-García; Alonso-Muñoz, 2017) o en la actividad parlamentaria ordinaria (Selva-Ruiz; Caro-Castaño, 2017).

El trabajo empírico de la investigación se ha centrado en la fase más intensa del proceso independentista en Cataluña: desde la aprobación de la fecha y la pregunta del referéndum del 1-O (junio 2017) hasta la puesta en libertad del President de la Generalitat Carles Puigdemont en Alemania (abril 2018). Dentro de un proceso de crisis institucional que arranca en 2012, es en esta fase final donde se concentran sus más graves consecuencias políticas, sociales y penales. La muestra incluye 10 perfiles de los principales líderes políticos catalanes y de ámbito estatal con un impacto significativo en Instagram. Y sus partidos representan respectivamente el 92,47\% y el $93,95 \%$ de los votos en las últimas elecciones generales de 2016 y autonómicas catalanas de 2017.

A partir de un modelo de análisis propio, el objetivo general de este trabajo es examinar el uso de Instagram por parte de los líderes políticos españoles en un contexto de grave crisis como el proceso independentista de Cataluña. En concreto, este estudio exploratorio se organiza a partir de los siguientes objetivos específicos sobre la gestión estratégica de la imagen política:

O1. Conocer el nivel de utilización entre los líderes políticos catalanes y estatales.

O2. Identificar las principales temáticas y funciones desarrolladas.

O3. Revisar el grado de personalización y los principales atributos profesionales y personales asignados.

O4. Estudiar los principales recursos expresivos empleados en torno a la selección de espacios, el tipo de puesta en escena, la utilización de recursos técnicos y el tipo de apelación al público.

Este conocimiento del uso político de Instagram ofrece claves actualizadas para valorar globalmente la incidencia de la espectacularización en la gestión digital de los líderes españoles y sus consecuencias democráticas. El debate en relación al impacto político de las redes sociales se encuentra en un momento de transición. Desde un optimismo inicial sobre sus efectos en el aumento del conocimiento y participación política (Gil-de-Zúñiga; Jung; Valenzuela, 2012), ha evolucionado hacia posiciones más matizadas debido a la existencia de frenos para el cambio social y político (De-Aguilera; Casero-Ripollés, 2018). Actualmente, tras la decisión británica de abandonar la Unión Europea (Brexit) y el triunfo electoral de Trump en Estados Unidos, se observa con preocupación el papel de las redes sociales como factor de polarización y desestabilización de los sistemas democráticos (Iosifidis; Wheeler, 2018). En este sentido, analizar el estilo comunicativo en una red en plena expansión como Instagram resulta clave para entender sus efectos en términos de participación democrática, o si está contribuyendo a una banalización de la política o incluso a un aumento de la polarización y el cinismo político.

\section{La espectacularización de la política $\mathbf{2 . 0}$}

En la última década la utilización de temas y recursos espectaculares se ha convertido en una tendencia habitual en el tratamiento de la política en los medios (Montagut; Carrillo, 2017) y en las estrategias de comunicación de los partidos (Lilleker; Tenscher; Štětka, 2015). Su aplicación en los medios españoles ha sido especialmente intensa, sobre todo en televisión (Pellisser-Rossell; Pineda, 2014), pero también en prensa, llegando incluso a secciones clásicas como economía e internacional (Berrocal-Gonzalo; Redondo-García; Torres-Chico, 2015).

A pesar de esta normalización de su uso, se trata de un fenómeno poco teorizado. En general, su estudio toma como base los recursos del infoentretenimiento televisivo (Jebril; Albaek; De-Vreese, 2013), y en esta línea, trabajos recientes concretan sus principales indicadores en el entorno mediático (Pellisser-Rossell; Pineda, 2014):

- protagonismo de temas ligeros, cercanos a lo anecdótico, por encima de los asuntos políticos, cívicos y públicos; - intensa personalización y asignación de roles a los actores 
políticos, descuidando el análisis estructural de problemas o situaciones;

tendencia hacia la emotividad y el enfoque humano en el tratamiento de la política, incluyendo la utilización del humor, la crítica o las relaciones personales;

- protagonismo de la acción individual por encima de la explicación de ideas;

- utilización de imágenes de formato espectacular en relación con el tipo de plano, escalas, perspectivas, localizaciones, puesta en escena, empleo de efectos, etc.

\subsection{Ejes de la espectacularización en redes sociales}

En paralelo a su aplicación en los medios, la llegada de las redes y consolidación progresiva de un "sistema comunicativo híbrido" (Chadwick, 2013) han supuesto un impulso hacia una mayor espectacularización de la política. En concreto, rasgos clave de este contexto como la bidireccionalidad entre producción y consumo, la escasa diferenciación entre hechos y opiniones, la confusión entre esferas pública y privada, o la mezcla información y entretenimiento (Casero-Ripollés; Ortells-Badenes; Rosique-Cedillo, 2014), favorecen la adopción de un estilo espectacular en redes como Instagram o Twitter.

En la espectacularización política 2.0 destaca la personalización como dinámica principal con un triple objetivo: concentrar el protagonismo en el líder, subrayar su competencia profesional y dar visibilidad a atributos personales

En esta espectacularización 2.0 destaca, por el momento, la personalización como dinámica principal (Enli; Skogerbø, 2013). Partidos y líderes han puesto el foco en la auto-presentación de sus candidatos. Y de esta forma, tratan de lograr tres objetivos (Van-Aelst; Sheafer; Stanyer, 2012):

- concentrar el protagonismo en el líder;

- subrayar su competencia profesional;

- dar visibilidad a atributos personales.

Esta estrategia de personalización digital presenta dos grandes ventajas (Balmas; Sheafer, 2013):

- simplifica el mensaje en un contexto de campaña permanente;

- contribuye a una conexión emocional con los ciudadanos.

Trabajos recientes muestran la utilidad de esta estrategia en mujeres políticas para desactivar estereotipos masculinos y construir sus propios atributos asociados a lo personal (McGregor; Lawrence; Cardona, 2017).

Una segunda tendencia relevante en la gestión de redes es la apuesta por la humanización y la autenticidad del líder (Bentivegna, 2015). Twitter o Instagram permiten mostrar la vida de los políticos de una forma cercana y espontánea (Ekman; Widholm, 2017). Contribuyen a humanizarlos y a lograr una aproximación más personal con los ciudadanos (Enli; Skogerbø, 2013). En este sentido, generan una potencial ilusión de cercanía que puede contribuir a mejorar la imagen pública del candidato (Selva-Ruiz; Caro-Castaño, 2017). Esta estrategia humanizadora sirve de base para un estilo populista que contrapone la autenticidad de los nuevos partidos, y sus líderes, como un valor frente al elitismo de la "política tradicional" (Enli, 2017).

En España, aunque el uso político de la vida privada ha sido poco relevante hasta el momento (Casero-Ripollés; Ortells-Badenes; Rosique-Cedillo, 2014), en el caso de Podemos sí que se detecta la utilización de un exitoso estilo populista en redes que apela a la humanización del líder y la conexión con "la gente" como sujeto político frente a las elites tradicionales (Casero-Ripollés; Sintes-Olivella; Franch, 2017).

Por último, como consecuencia de la exposición personalista en redes, muchos políticos se han convertido en personajes próximos a la cultura "celebrity" (Oliva; Pérez-Latorre; Besalú, 2015). Desde un punto de vista práctico, esta "celebritización" de la política se basa en la (auto)presentación del líder a partir de rasgos extraordinarios (carisma, telegenia, atractivo, etc.), junto a otros ordinarios que refuerzan su autenticidad a través de su estilo de vida, sus relaciones personales y una notable apertura emocional (Lalancette; Reynauld, 2017).

Tradicionalmente, en el debate sobre efectos democráticos de la espectacularización de la información política encontramos dos posturas (Casero-Ripollés; Ortells-Badenes; Rosique-Cedillo, 2014):

- aquellos que consideran que trivializa el debate público y destacan sus consecuencias negativas, fundamentalmente la superficialidad del mensaje y el aumento del cinismo político;

- aquellos que ponen el foco en su enorme potencial para ampliar la agenda informativa, atraer nuevos públicos al debate social y aumentar la participación electoral (Jebril; Albaek; De-Vreese, 2013).

En la actualidad este debate ha evolucionado hacia una postura intermedia más matizada. En general, existe consenso en valorar de forma positiva un uso moderado, no sensacionalista, de este estilo en medios sociales por su capacidad de atraer al público joven y aumentar la participación política (Montagut; Carrillo, 2017). Sin embargo, la mera presencia en redes no es suficiente. Factores como la naturalidad, la autenticidad o la apuesta por una gestión interactiva, resultan decisivos para conquistar la confianza de los ciudadanos (McGregor; Lawrence; Cardona, 2017), y lograr los efectos democratizadores e inclusivos comentados (Loader; Vromen; Xenos, 2016).

\section{Instagram y la gestión de la imagen política}

Varios motivos impulsan la profesionalización del uso de imágenes en redes sociales y el desarrollo de una gestión estratégica por parte de partidos y líderes políticos (Lalancette; Raynauld, 2017):

- efectividad de la imagen para (auto)presentarse de forma integral y atractiva: a través de su actividad diaria en las redes se realiza un "empaquetado visual" que mezcla elementos de la vida profesional y personal con gran dinamismo (Ekman; Widholm, 2017); 
- la imagen potencia el establecimiento de conexiones significativas con la audiencia: gracias al uso de las redes, lo visual genera un fuerte impacto en la atención del público y ayuda a trasmitir eficazmente argumentos persuasivos (Schill, 2012; Enli; Skogerbø, 2013);

- una gestión innovadora y visual en las redes contribuye eficazmente a la movilización electoral, la presentación estratégica de los candidatos y genera sinergias con otras herramientas tradicionales (Filimonov; Russmann; Svensson, 2016).

Esta utilidad profesional ha hecho aumentar el interés investigador sobre los efectos de la imagen política en redes como Twitter o Facebook. En concreto, trabajos recientes demuestran una influencia significativa sobre la percepción de atributos de los líderes en campaña (Goodnow, 2013), en las rutinas de los medios (Marland, 2012) y de forma más amplia en el encuadre de temas políticos (Powell et al., 2015). En España, los primeros trabajos sobre la imagen en Twitter muestran una notable personalización sobre el líder en campañas (Quevedo-Redondo; Portalés-Oliva; Berrocal-Gonzalo, 2016), pero sin un patrón claro respecto a la representación de atributos ni un uso relevante de la vida privada.

\section{En España Instagram se ha consolidado en las campañas electorales de 2015 y 2016 como una plataforma eficaz}

\subsection{Principales tendencias en el uso político de Ins- tagram}

En apenas un ciclo electoral desde 2012, Instagram se ha convertido en un medio de difusión de mensajes empleado a diario por partidos y líderes políticos. En España su uso se ha consolidado en las campañas de 2015 y 2016 (Quevedo-Redondo; Portalés-Oliva, 2017). En este breve período de tiempo se ha mostrado como una plataforma eficaz para potenciar la comunicación directa con los ciudadanos, recaudar fondos, movilizar al electorado e incluso generar ciertos efectos sobre la agenda de campaña (Eldin, 2016; Towner; Muñoz, 2017). Aunque todavía nos hallamos en una fase exploratoria, trabajos recientes señalan una profesionalización básica, dos grandes ámbitos de aplicación, campañas y construcción de liderazgo, y algunas tendencias de uso significativas (Lalancette; Raynauld, 2017).

En campaña electoral destaca la utilización de una fotografía estándar, bastante mediatizada, siendo todavía muy secundaria la presencia de otros formatos de imagen como el vídeo, la selfie o el collage. Globalmente, en Instagram se detectan unas funciones bastante convencionales (Filimonov; Russmann; Svensson, 2016), en línea con las detectadas en Twitter (López-Meri; Marcos-García; Casero-Ripollés, 2017):

- uso propagandístico para dar visibilidad a mítines, actos, y apariciones en medios del candidato;

- alta personalización entorno al líder;

- protagonismo del contexto público, y la realización de actividades profesionales, desaprovechando la cercanía y autenticidad que ofrecen los espacios más personales.

En España el uso de Instagram durante las campañas encaja en estos rasgos generales, pero añadiendo dos matices importantes:

- a pesar de la disparidad en los atributos presentados, la humanización, poco a poco, se abre paso (Marcos-García; Alonso-Muñoz, 2017);

- se detecta también una incipiente "celebritización" de los políticos basada en roles populistas y una apelación emocional al votante (Quevedo-Redondo; Portalés-Oliva, 2017).

Otro ámbito importante de aplicación es la (auto)construcción de liderazgo en el día a día político. El caso del primer ministro canadiense, Justin Trudeau (Lalancette; Raynauld, 2017) ofrece una receta de éxito basada en el uso regular de la plataforma, una alta personalización, una cuidada puesta en escena y la autenticidad para combinar contextos políticos, públicos y privados de forma natural (Loader; Vromen; Xenos, 2016). En España, también se ha analizado el uso cotidiano de Instagram para la humanización de los políticos (Selva-Ruiz; Caro-Castaño, 2017). Sin embargo, los resultados iniciales al respecto son muy limitados: sólo algunos parlamentarios de nuevos partidos apuestan por dar una mayor presencia a espacios y actividades privadas, frente al estilo público y profesional de la mayoría.

\section{Metodología. Las $5 \mathrm{~W}$ de la imagen política en redes sociales}

La metodología empleada se basa en un análisis de contenido (Igartua, 2006). Esta técnica cuantitativa va a permitir la revisión objetiva y sistemática de las principales características de la imagen política en Instagram, tomando como unidad de registro cada publicación en esta red social. De cara a obtener una mirada completa y coherente sobre el fenómeno, se propone un modelo de análisis inspirado en la estructura en las 5 W's periodísticas (qué, quién, dónde, cuándo y cómo). Dentro de este modelo se plantean nueve categorías de análisis que repasan de forma integral los principales rasgos temáticos y formales asociados a la espectacularización de la política.

Para la selección de las categorías de análisis se han tenido en cuenta estudios precedentes que examinan la utilización de la imagen política en redes sociales (Goodnow, 2013; López-Rabadán; López-Meri; Doménech-Fabregat, 2016), y trabajos específicos sobre el uso de Instagram (Marcos-García; Alonso-Muñoz, 2017; Quevedo-Redondo; Portalés-Oliva, 2017; Selva-Ruiz; Caro-Castaño, 2017, Lalancette; Raynauld, 2017).

Para garantizar la fiabilidad y homogeneidad del estudio, se apuesta por categorías descriptivas de bajo nivel de inferencia (Bardin, 2002). Y para objetivar al máximo aquellas más interpretativas (funciones de la imagen y asignación de atributos) se han tomado como referencia estudios recientes sobre el uso de Twitter (López-Meri; Marcos-García; Casero-Ripollés, 2017) o la gestión de la imagen en otros soportes (García-Beaudoux; D’Adamo, 2006). Esta propuesta metodológica se muestra en la tabla 1. 
Tabla 1. Modelo de análisis "Las 5W de la espectacularización de la imagen digital"

\begin{tabular}{|c|c|}
\hline 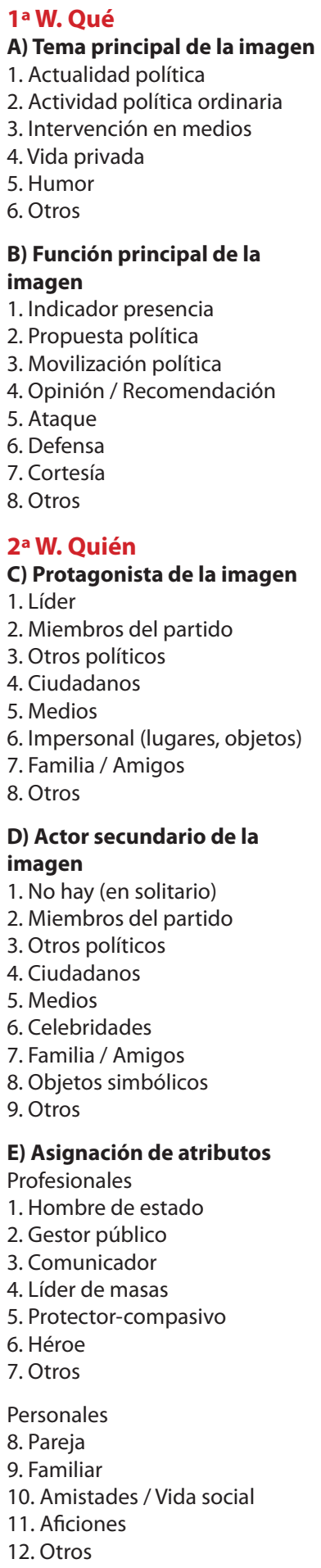 & $\begin{array}{l}\text { 3a W. Dónde } \\
\text { F) Espacio de la imagen } \\
\text { 1. Indeterminado } \\
\text { 2. Oficial } \\
\text { 3. Público } \\
\text { 4. Privado } \\
\text { 5. Mediático } \\
\text { 6. Otros } \\
\text { 4a W. Cuándo } \\
\text { G) Puesta en escena } \\
\text { 1. Institucional } \\
\text { 2. Espontaneidad estratégica } \\
\text { 3. Amateur } \\
\text { 4. Posado artificioso } \\
\text { 5. Otros } \\
\text { 5a W. Cómo } \\
\text { H) Aspectos técnicos } \\
\text { - Formato (1. Fotografía, 2. Selfies, } \\
\text { 3. Cartel. 4. Vídeo) } \\
\text { - Tipo de plano (1. General, } 2 . \\
\text { Entero-medio, 3. Primer plano, } 4 . \\
\text { Detalle) } \\
\text { - Ángulo plano (1. Neutro, } 2 . \\
\text { Picado, 3. Contrapicado) } \\
\text { - Tipo iluminación (1. Neutra, } 2 . \\
\text { Clave alta, 3. Clave baja) } \\
\text { - Efectos posproducción (1. Nin- } \\
\text { guno, 2. Rótulos, 3. Etiquetas, } 4 . \\
\text { Filtros, } 5 . \text { Galerías, } 6 . \text { Collages) } \\
\text { I) Tipo de apelación } \\
\text { 1. Racional } \\
\text { 2. Emocional positiva } \\
\text { 3. Emocional negativa } \\
\text { 4. Indeterminada }\end{array}$ \\
\hline
\end{tabular}

La definición final de la muestra se ha acotado a partir de dos criterios. Desde un punto de vista temporal, se han seleccionado ocho momentos clave (tabla 2) dentro de la fase más intensa del proceso independentista que incluyen:

- referéndum del 1-0;

- declaración unilateral de independencia del 27 de octubre;

- aplicación del artículo 155 de la Constitución española;

- encarcelación de políticos;
- celebración de las elecciones autonómicas anticipadas el 21 de diciembre de 2017;

- procesamiento del President Puigdemont en Alemania.

En total se han examinado 188 publicaciones. En la tabla 2 se ofrecen detalles sobre la distribución temporal de la muestra.

En relación con los actores seleccionados, la muestra se ajusta a lo publicado por una selección exploratoria de 10 perfiles de Instagram que incluyen a los presidentes de ambos gobiernos, y líderes y portavoces de los partidos más importantes del mapa político catalán y estatal. Además, se ha verificado que presentan una actividad regular a lo largo de todo el período analizado y un volumen significativo de seguidores en la Red. La composición equilibrada y la relevancia de esta muestra va a permitir comparar los resultados en diferentes niveles, tanto institucionales como ideológicos y temporales. En la tabla 3 se ofrece la información completa sobre los perfiles analizados.

Las unidades de la muestra se han extraído manualmente de los diez perfiles de Instagram seleccionados. Tras su codificación, el tratamiento estadístico de los resultados se ha realizado mediante el programa SPSS (v.23). La fiabilidad de los intercodificadores se ha calculado con la fórmula Pi de Scott, alcanzando un nivel de 0,94.

\section{Resultados}

Una vez aplicado el modelo metodológico propuesto, los resultados confirman un uso regular y normalizado de Instagram por parte de los actores políticos. Al mismo tiempo es posible identificar tendencias significativas en cada una de las categorías de análisis revisadas.

En la Tabla 4 se ofrece un resumen general de los resultados obtenidos en cada categoría sobre la espectacularización de la imagen política en Instagram.

Tabla 2. Distribución temporal de la muestra

\begin{tabular}{|c|c|c|c|}
\hline \multirow[t]{2}{*}{ Fecha } & \multirow[t]{2}{*}{ Acontecimiento } & \multicolumn{2}{|c|}{$\begin{array}{l}\text { Unidades de } \\
\text { análisis }\end{array}$} \\
\hline & & $\mathbf{n}$ & $\%$ \\
\hline 9-10 junio & $\begin{array}{l}\text { Presentación fecha y pregunta del } \\
\text { referéndum }\end{array}$ & 15 & 7,9 \\
\hline $\begin{array}{l}\text { 5-7 septiem- } \\
\text { bre }\end{array}$ & $\begin{array}{l}\text { Aprobación leyes del referéndum y } \\
\text { transitoriedad }\end{array}$ & 35 & 18,6 \\
\hline 11 septiembre & Diada Nacional de Cataluña & 11 & 5,8 \\
\hline 1-3 octubre & Celebración referéndum del 1-O & 21 & 11,1 \\
\hline 27-31 octubre & $\begin{array}{l}\text { Declaración unilateral de inde- } \\
\text { pendencia (DUI) y aplicación del } \\
\text { artículo } 155\end{array}$ & 53 & 28,1 \\
\hline 21 diciembre & $\begin{array}{l}\text { Elecciones autonómicas anticipa- } \\
\text { das } 21-D\end{array}$ & 13 & 6,9 \\
\hline 22-27 marzo & $\begin{array}{l}\text { Detención de Carles Puigdemont } \\
\text { en Alemania }\end{array}$ & 30 & 15,9 \\
\hline \multirow[t]{2}{*}{6 abril } & $\begin{array}{l}\text { Puesta en libertad de Carles Puig- } \\
\text { demont en Alemania }\end{array}$ & 10 & 5,3 \\
\hline & Total & 188 & 100 \\
\hline
\end{tabular}


Tabla 3. Distribución de la muestra por perfiles analizados

\begin{tabular}{|c|c|c|c|c|}
\hline \multirow{2}{*}{ Biografía del perfil en Instagram } & \multirow{2}{*}{ Usuario } & \multirow{2}{*}{$\begin{array}{l}\text { Seguidores } \\
\text { (mayo 2018) }\end{array}$} & \multicolumn{2}{|c|}{ Unidades de análisis } \\
\hline & & & $\mathbf{n}$ & $\%$ \\
\hline $\begin{array}{l}\text { Carles Puigdemont } \\
\text { 130è President de Catalunya governrepublica.org }\end{array}$ & @carlespuigdemont & $225 \mathrm{~K}$ & 26 & 13,8 \\
\hline $\begin{array}{l}\text { Oriol Junqueras } \\
\text { Veí de Sant Vicenç dels Horts. President d'ERC. Perfil a càrrec } \\
\text { gabinet. }\end{array}$ & & $94,2 \mathrm{~K}$ & 16 & 8,5 \\
\hline $\begin{array}{l}\text { Albert Rivera } \\
\text { Vive y deja vivir. } \\
\text { http://www.albertrivera.info }\end{array}$ & @albertriveradiaz & $81,3 \mathrm{~K}$ & 32 & 17,0 \\
\hline $\begin{array}{l}\text { Pablo Iglesias } \\
\text { Secretaría general de @ahorapodemos } \\
\text { Diputado en el Congreso. } \\
\text { Nadie duda de que este país ya ha cambiado. ¡Sí se puede! }\end{array}$ & @iglesiasturrionpablo & $71 \mathrm{~K}$ & 5 & 2,7 \\
\hline $\begin{array}{l}\text { Inés Arrimadas } \\
\text { Trotamundos }\end{array}$ & @inesarrimadas & $71 \mathrm{~K}$ & 9 & 4,8 \\
\hline $\begin{array}{l}\text { Mariano Rajoy } \\
\text { Presidente del Gobierno y del PP. Casado, padre de dos hijos. } \\
\text { Trabajo por una \#España con más empleo, oportunidades y } \\
\text { bienestar. } \\
\text { http://www.facebook.com/marianorajoy }\end{array}$ & @marianorajoy & $69,9 \mathrm{~K}$ & 20 & 10,7 \\
\hline $\begin{array}{l}\text { Gabriel Rufián } \\
\text { Graduado social. Diputado de @esquerrarepublicana en el } \\
\text { Congreso. Vivo con mi mujer y mi hijo en Sabadell } \\
\text { http://gabrielrufian.cat }\end{array}$ & @gabrielrufian & $58,5 \mathrm{~K}$ & 28 & 14,9 \\
\hline $\begin{array}{l}\text { Pedro Sánchez } \\
\text { Padre. Doctor en Economía. Secretario General del PSOE. } \\
\text { http://www.sanchezcastejon.es }\end{array}$ & @sanchezcastejon & $35,3 \mathrm{~K}$ & 39 & 20,7 \\
\hline $\begin{array}{l}\text { Miquel Iceta } \\
\text { Primer secretari del PSC i candidat socialista a la Presidència de } \\
\text { la Generalitat } \\
\text { http://www.miqueliceta.cat }\end{array}$ & @miqueliceta & $4 \mathrm{~K}$ & 4 & 2,1 \\
\hline $\begin{array}{l}\text { Xavier Domènech } \\
\text { Historiador, activista i a voltes moltes altres coses. Coordinador } \\
\text { General de Catalunya en Comú }\end{array}$ & @xavierdomenechs & $2,5 \mathrm{~K}$ & 9 & 4,8 \\
\hline Total & & & 188 & 100 \\
\hline
\end{tabular}


Tabla 4. Resumen general de los resultados obtenidos $(n=188)$

\begin{tabular}{|c|c|c|c|c|}
\hline & Categoría de análisis & Rasgos temáticos y formales & $\mathbf{n}$ & $\%$ \\
\hline \multirow{8}{*}{ Qué } & \multirow{4}{*}{ Tema principal } & Actualidad política & 62 & 33,0 \\
\hline & & Actividad política ordinaria & 62 & 33,0 \\
\hline & & Actividad en medios & 23 & 12,2 \\
\hline & & Vida privada & 15 & 8,0 \\
\hline & \multirow{4}{*}{ Función principal } & Indicador presencia & 80 & 42,5 \\
\hline & & Cortesía / Agradecimiento & 33 & 17,5 \\
\hline & & Opinión / Recomendación & 21 & 11,1 \\
\hline & & Movilización / Participación & 17 & 9,0 \\
\hline \multirow{12}{*}{ Quién } & \multirow{4}{*}{ Protagonista de la imagen } & Líder en solitario & 124 & 65,5 \\
\hline & & Impersonal & 22 & 11,7 \\
\hline & & Ciudadanos & 19 & 10,1 \\
\hline & & Miembros del partido & 12 & 6,4 \\
\hline & \multirow{4}{*}{ Atributos profesionales } & Comunicador & 44 & 23,4 \\
\hline & & Hombre de estado & 38 & 20,2 \\
\hline & & Líder de masas & 26 & 13,8 \\
\hline & & Gestor público & 14 & 7,4 \\
\hline & \multirow{4}{*}{ Atributos personales } & Aficiones & 7 & 3,7 \\
\hline & & Amistades / Vida social & 3 & 1,6 \\
\hline & & Familia & 3 & 1,6 \\
\hline & & Pareja & 0 & 0,0 \\
\hline \multirow{4}{*}{ Dónde } & \multirow{4}{*}{ Espacio de la imagen } & Oficial & 78 & 41,4 \\
\hline & & Público & 69 & 36,7 \\
\hline & & Indeterminado & 22 & 11,7 \\
\hline & & Mediático & 9 & 4,7 \\
\hline \multirow{4}{*}{ Cuándo } & \multirow{4}{*}{ Puesta en escena } & Espontaneidad estratégica & 78 & 41,5 \\
\hline & & Amateur & 43 & 22,8 \\
\hline & & Institucional & 26 & 13,8 \\
\hline & & Posado artificioso & 24 & 12,7 \\
\hline \multirow{8}{*}{ Cómo } & \multirow{5}{*}{ Aspectos técnicos } & $\begin{array}{l}\text { Formato } \\
\text { Imagen fotográfica } \\
\text { Selfies }\end{array}$ & $\begin{array}{c}167 \\
3\end{array}$ & $\begin{array}{r}88,8 \\
1,6\end{array}$ \\
\hline & & $\begin{array}{l}\text { Tipo de plano } \\
\text { Entero-medio } \\
\text { General }\end{array}$ & $\begin{array}{l}90 \\
70\end{array}$ & $\begin{array}{l}47,9 \\
37,2\end{array}$ \\
\hline & & $\begin{array}{l}\text { Ángulo plano } \\
\text { Neutro } \\
\text { Picado } \\
\text { Contrapicado }\end{array}$ & $\begin{array}{l}99 \\
50 \\
39\end{array}$ & $\begin{array}{l}52,6 \\
26,6 \\
20,7\end{array}$ \\
\hline & & $\begin{array}{l}\text { Tipo iluminación } \\
\text { Clave media } \\
\text { Clave baja }\end{array}$ & $\begin{array}{c}121 \\
28\end{array}$ & $\begin{array}{l}64,3 \\
25,5\end{array}$ \\
\hline & & $\begin{array}{l}\text { Efectos } \\
\text { Sin efectos } \\
\text { Galerías } \\
\text { Etiquetas } \\
\text { Filtros }\end{array}$ & $\begin{array}{l}78 \\
67 \\
20 \\
18\end{array}$ & $\begin{array}{r}41,5 \\
35,6 \\
10,6 \\
9,6\end{array}$ \\
\hline & \multirow{3}{*}{ Tipo de apelación } & Emocional positiva & 94 & 50,0 \\
\hline & & Racional & 71 & 37,7 \\
\hline & & Emocional negativa & 4 & 2,1 \\
\hline
\end{tabular}

\subsection{Qué / Tema principal}

Respecto a la agenda temática, destaca la representación de la actividad profesional de los líderes, tanto a través de acontecimientos marcados por la actualidad, normalmente plenos o manifestaciones (33\%) (imagen 1); como por la representación de cuestiones más costumbristas de su día a día, encuadrados en la categoría la "actividad política ordinaria" (33\%) (imagen 2). Este día a día se materializa principalmente en reuniones o actos de partido. La prioridad es siempre mostrar su actividad profesional de forma dinámica y actualizada.

El resto de los temas tiene una visibilidad mucho menor. La presencia en "Medios de comunicación" (12,23\%) o la representación de la "Vida privada" (7,97\%) (imagen 3) son contenidos claramente secundarios, y respecto al "Humor", ni siquiera se detectan ejemplos en la muestra. En este sentido, se considera que los líderes desaprovechan la capacidad de esta plataforma para ofrecer una comunicación más cercana y diversificada en su agenda.

\section{Función principal}

Respecto al uso estratégico de Instagram, el análisis revela que la función dominante corresponde a la categoría "Indicador de presencia" (42,55\%). Casi en la mitad de las ocasiones se utiliza la imagen para dar testimonio de que el líder ha estado presente en un lugar o acontecimiento $y$, al mismo tiempo, profundizar en la autopromoción de determinados atributos. Un ejemplo claro de esta función son las imágenes de la asistencia al colegio electoral el día del referéndum (imagen 4).

Más allá de este uso mayoritario meramente representativo, se detecta una segunda función vinculada a la interacción social, 

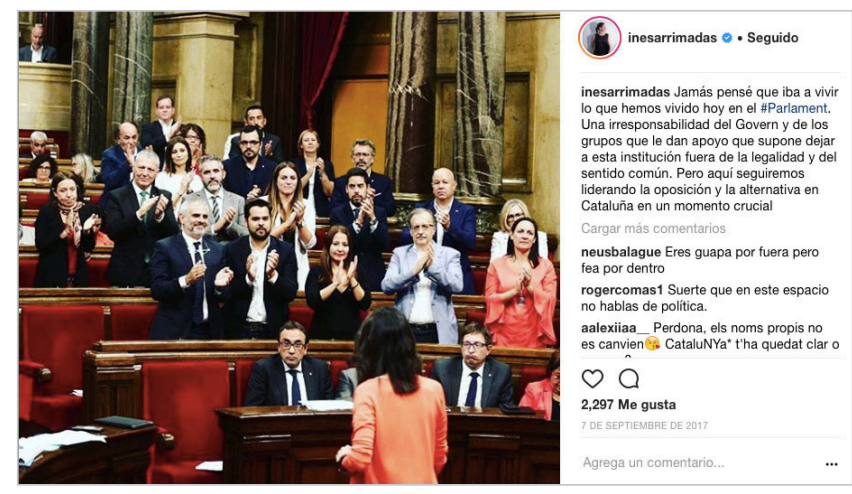

Imagen 1. "Actualidad política"

bien como muestra de cortesía y agradecimiento $(17,55 \%)$ (imagen 5) o bien aquellas que tienen por objetivo expresar opiniones o recomendaciones sobre un tema $(11,17 \%)$.

Llama la atención el rol secundario de funciones políticas clásicas como "Movilización" (9,04\%), "Propuesta política" $(7,47 \%)$ o "Ataque al adversario" (3,72\%). Aunque en ocasiones se logra un aprovechamiento bastante emotivo a la hora de mostrar la presencia del líder, de nuevo se identifica un uso limitado y una cierta infrautilización de Instagram para dinamizar la comunicación de los líderes a través de funciones políticas más operativas.

La función dominante corresponde a la categoría "Indicador de presencia". Casi en la mitad de las ocasiones la imagen se utiliza para dar testimonio de que el líder ha estado presente en un lugar o acontecimiento y profundizar en la autopromoción de determinados atributos

\subsection{Quién / Gestión del protagonismo}

La tendencia general es ofrecer un claro protagonismo visual al líder. Esta potente estrategia de personalización se concreta en una altísima presencia del dirigente político en la muestra analizada (88,83\%), bien como protagonista de sus propias fotografías $(66,5 \%)$ o como actor secundario de las mismas (22,34\%). En sintonía con estudios precedentes,
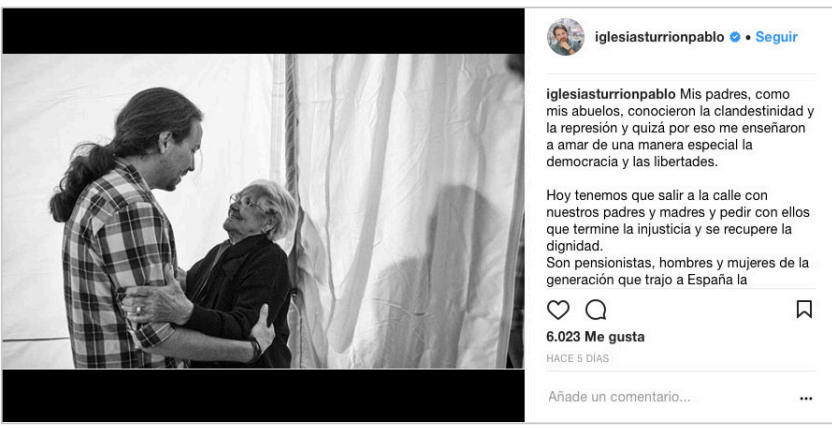

Imagen 5. "Cortesía / Agradecimiento"

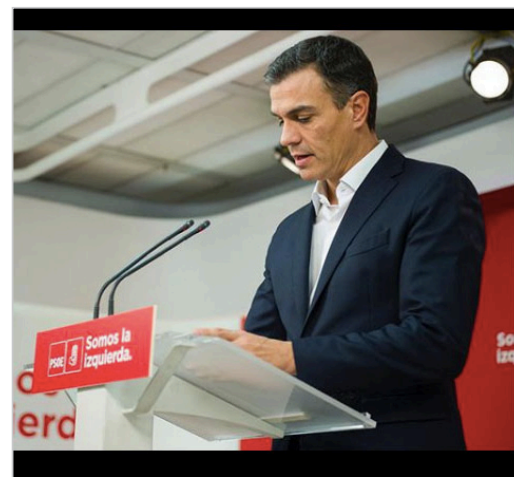

(2)

sanchezcastejon Apelo a la confianza, sensatez $y$ la serenidad, ahora Estado de derechey y Estatutución, Autonomia. Unidos hemos superado las
adversidades $y$ lo volveremos a hacer. Co ley y politica. Con el respeto al diferente, el chogolationa.

tperezcepeda Gracias, por haber hecho lo imposible por evitarlo.

$\mathrm{OO}$

1,212 Me gusta

TDE OCTUBRE DE 2

Imagen 2. "Actividad política ordinaria"

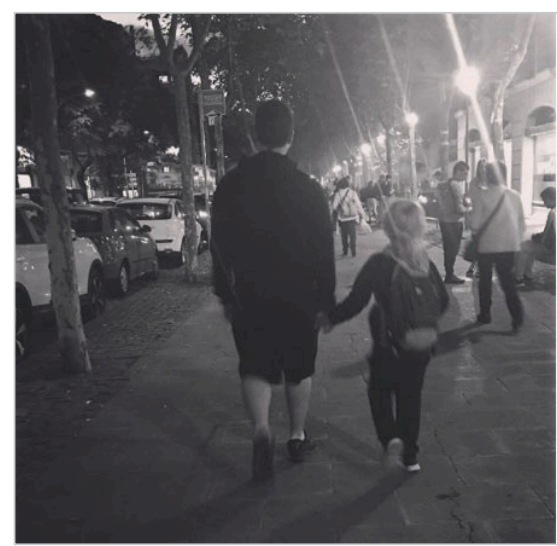

(3)

gabrielrufian THE ROAD NOT TAKEN Two roads diverged in a yellow wood And sorry I could not travel both And be one traveler, long I stood And looked down one as far as I could To where it bent in the undergrowuth
Then took the other, as sust as tait: And having perhaps the better claim Because it was grassy and wanted Though as tor that the passing there Had worn them really about the same.
And both that morning equally lay $\mathrm{O} \mathrm{C}$ 5.636 Me gusta

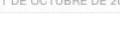

Imagen 3. "Vida privada"

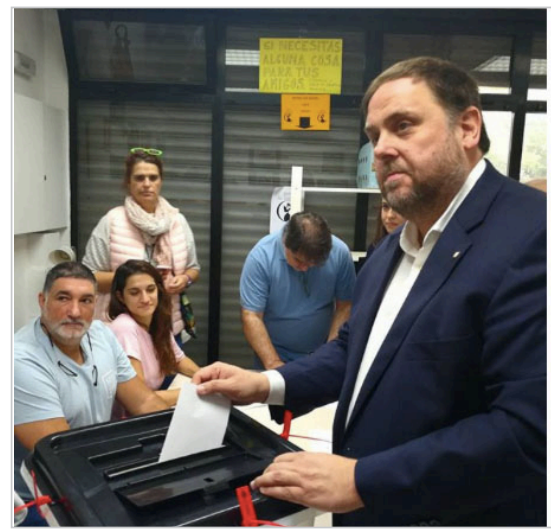

(8)

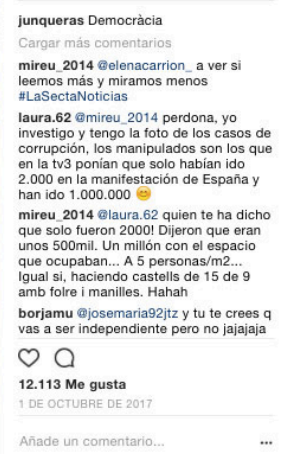

Imagen 4. "Indicador de presencia"

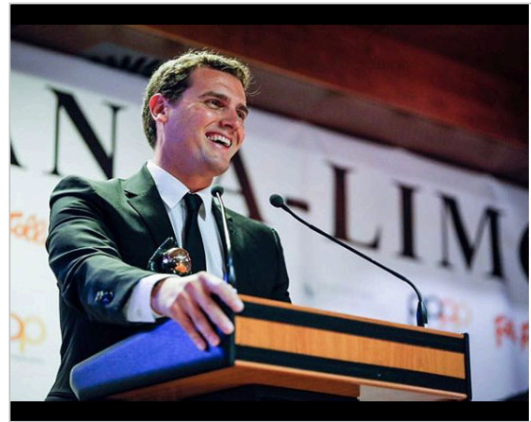

3 albertiveradiaz Ha sido un honor haber
reciticivo recibido esta noche el Premio Narania 0
edicion 2016. Gracias a los compañeros de prensa por vuestro imprescindible cmurria th th the giulscanales $\nabla$ lauramarin11 Que lastima que no puedas 00 2,322 Me gusta Imagen 6. "Líder en solitario" 

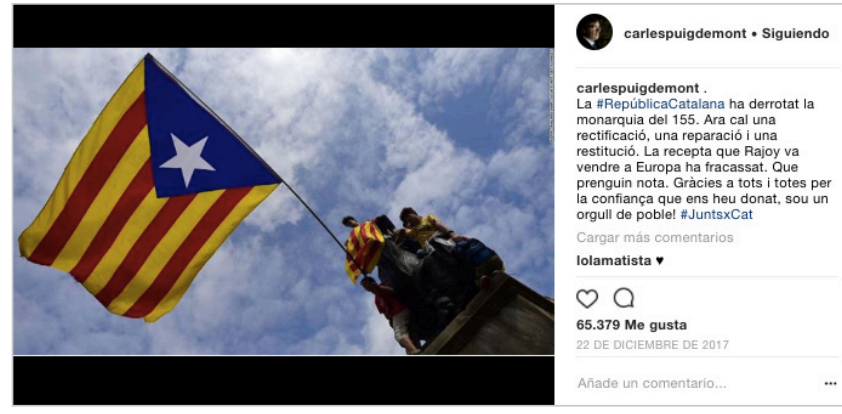

Imagen 7. Protagonismo "Impersonal"
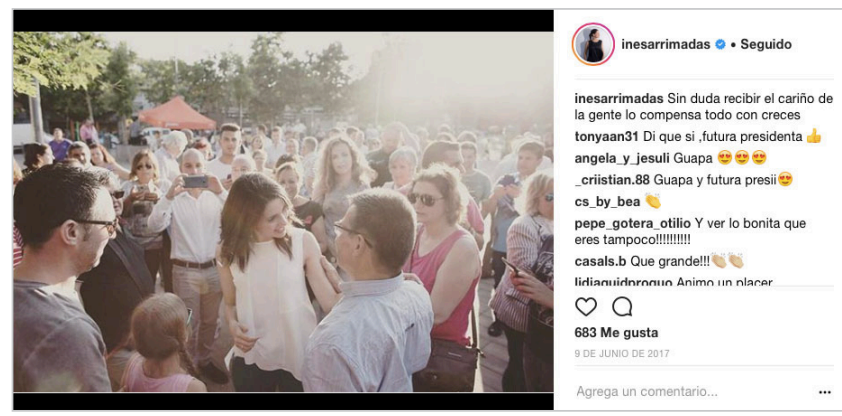

Imagen 9. "Actores secundarios / Ciudadanos"
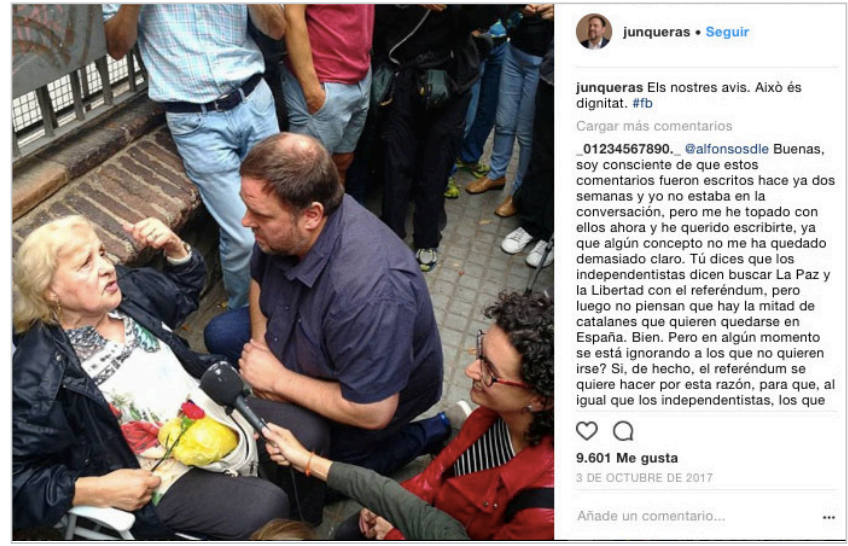

Imagen 10. "Actores secundarios-Ciudadanos"
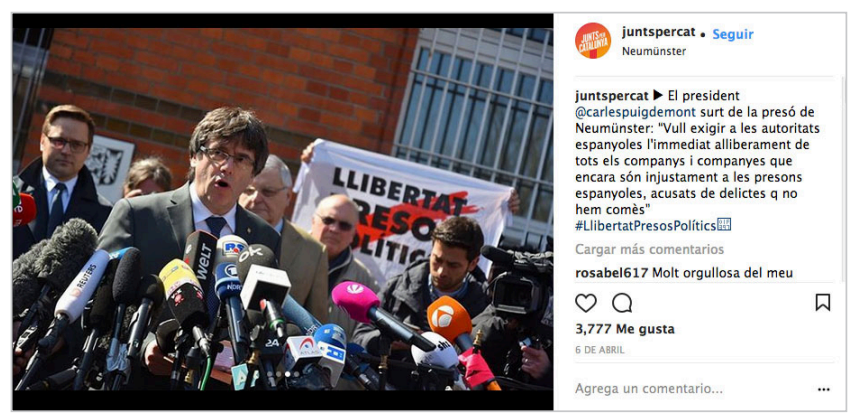

Imagen 11. Atributo profesional "Comunicador"
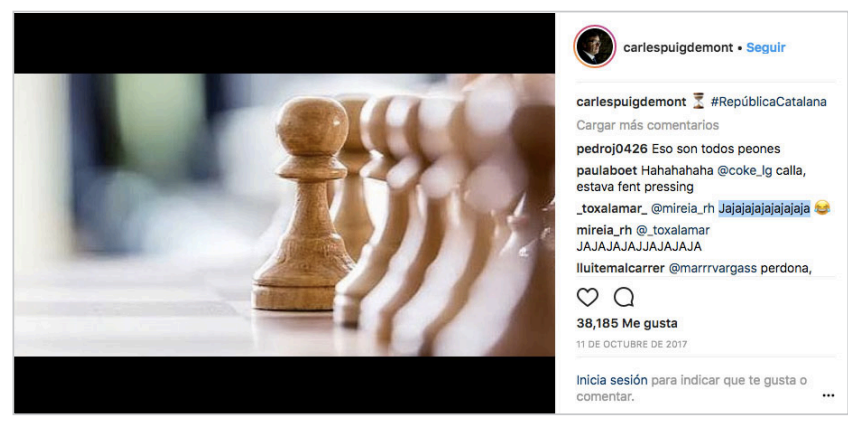

Imagen 8. Protagonismo "Impersonal"

se confirma la presencia en solitario del líder en una proporción muy significativa (44,15\%) (imagen 6). En gran medida Instagram funciona como un álbum personal de los líderes.

Por el contrario, el resto de potenciales protagonistas tiene una presencia bastante limitada como sujeto central de la imagen. En este sentido, cabe destacar el protagonismo que alcanzan paisajes, lugares, objetos..., englobados dentro de la categoría "Impersonal" (12\%) (imágenes 7 y 8 ) o la presencia puntual de ciudadanos (10\%). Sin embargo, apenas se utiliza para dar visibilidad a compañeros de partido $(6,3 \%)$.

Es en el rol de actores secundarios donde los ciudadanos $(23,94 \%)$ (imágenes 9 y 10), compañeros de partido $(18,08 \%)$, y objetos simbólicos como banderas o edificios oficiales $(14,89 \%)$ cumplen un papel estratégico capital. Bien para subrayar la función propagandística de la imagen o para caracterizar el líder de forma expresiva. Destaca la exigua utilización de famosos y celebridades $(2,66 \%)$. Estos datos constatan la intensa estrategia de personalización desarrollada en esta red social, en la que el líder se convierte en un icono sobre el que pivota el resto de contenidos.

\section{En las situaciones de crisis política la imagen está sirviendo para reforzar sus roles profesionales más tradicionales}

\section{Asignación de atributos profesionales y personales}

En relación a la asignación de los atributos profesionales, destaca la representación de cualidades racionales (51,06\%) por encima de las emocionales (31,38\%). En este sentido, los líderes son presentados principalmente como grandes comunicadores $(23,40 \%)$ (imagen 11$)$ o como representantes institucionales $(20,21 \%)$ (imagen 12$)$. Se interpreta que en las situaciones de crisis política la imagen está sirviendo para reforzar sus roles profesionales más tradicionales.

La única cualidad emocional destacable en las imágenes analizadas es la de "Líder de masas" (13,82\%) (imagen 13). De nuevo, de forma coherente con los temas y funciones explicados previamente, tan sólo un 6,9\% de las imágenes se asocian con atributos personales como, por ejemplo, mostrar las aficiones $(3,72 \%)$, la vida familiar $(1,6 \%)$ o las amistades $(1,6 \%)$. 


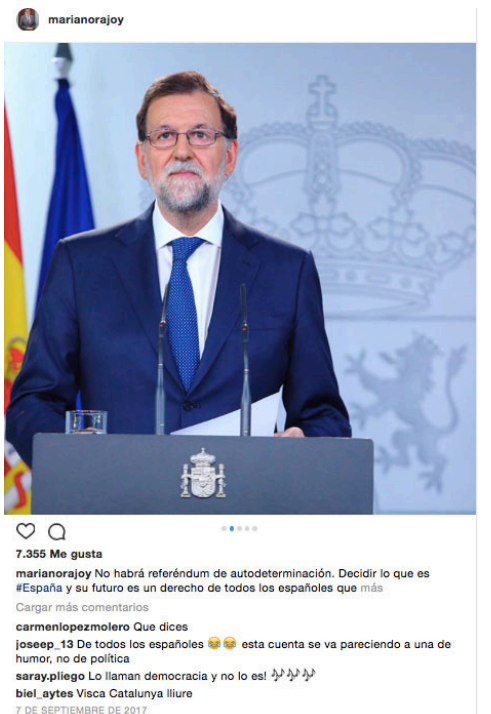

Imagen 12. Atributo profesional "Hombre de estado"

\subsection{Dónde / Gestión del espacio}

De acuerdo con las funciones indicadas con anterioridad, la tendencia principal es a representar los escenarios del poder y de enfrentamiento ideológico. Bien mostrando espacios de carácter oficial: parlamentos, despachos o salas de prensa (41,43\%) (imagen 14), o bien dando protagonismo a todos los actos políticos desarrollados en espacios públicos, principalmente manifestaciones en calles y plazas $(36,70 \%)$ (imagen 15). En este sentido, Instagram sí que resulta efectivo para combinar de forma regular y dinámica los dos grandes escenarios de la crisis independentista:

- el enfrentamiento parlamentario;

- la protesta social en las calles de Cataluña.

Del resto de espacios representados, sólo resulta significativo destacar lo irrelevante de la presencia de contextos privados $(2,66 \%)$. Y, además, subrayar la tendencia de no mostrar con claridad el lugar exacto donde han sido tomadas las fotografías. Esta apuesta por ubicar la imagen en un espacio indeterminado resulta significativa $(11,70 \%)$.

\subsection{Cuándo / Puesta en escena}

Respecto al tipo de puesta en escena, se detecta un dominio creciente de las claves visuales de la plataforma en cuanto a naturalidad y dinamismo. En este sentido, el estilo más extendido es el de "Espontaneidad estratégica" (41,49\%) (imagen 16). Este tipo de fotografías son resultado de una correcta planificación, en la que los líderes son conscientes de la presencia de las cámaras pero incluso así logran trasmitir naturalidad en el desarrollo de sus acciones. Los fotógrafos logran sintetizar de forma atractiva, y en ocasiones espectacular, el ambiente natural del momento político. Sin duda, es una de las mejores pruebas de la profesionalización en el uso político de Instagram.

Sin embargo, la presencia significativa de estilos problemáticos y poco profesionales, como el "Amateur" $(22,87)$ (imagen 17) o el "Posado" (12,76\%), indica la existencia de un amplio margen de mejora en la gestión de la imagen en algunos perfiles. Afortunadamente, un estilo tradicional
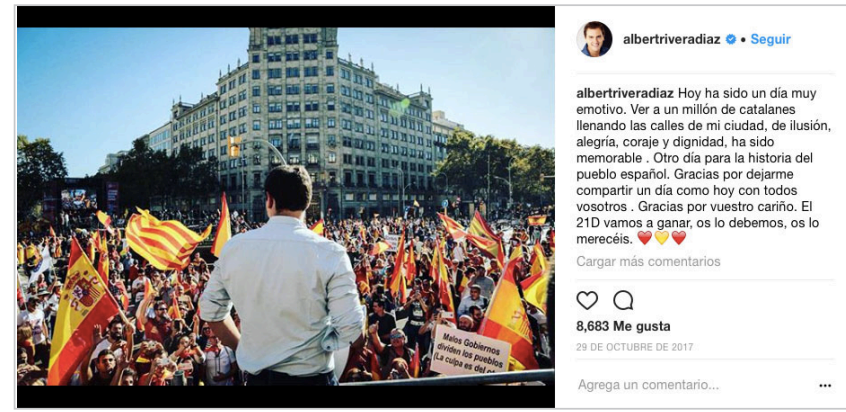

Imagen 13. Atributo profesional "Líder de masas"
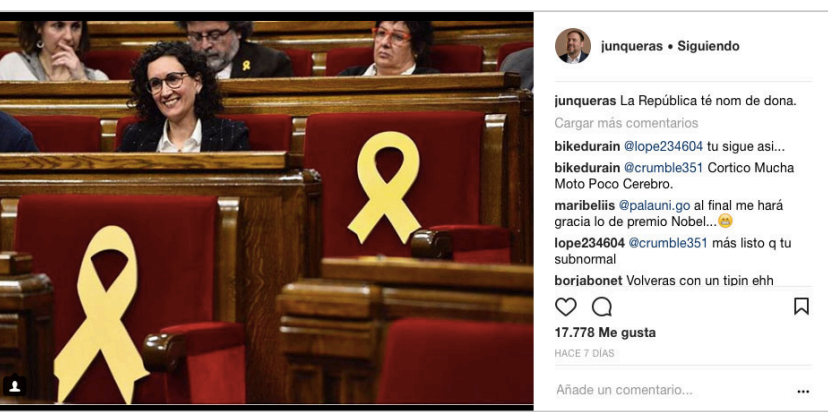

Imagen 14. "Espacio oficial"
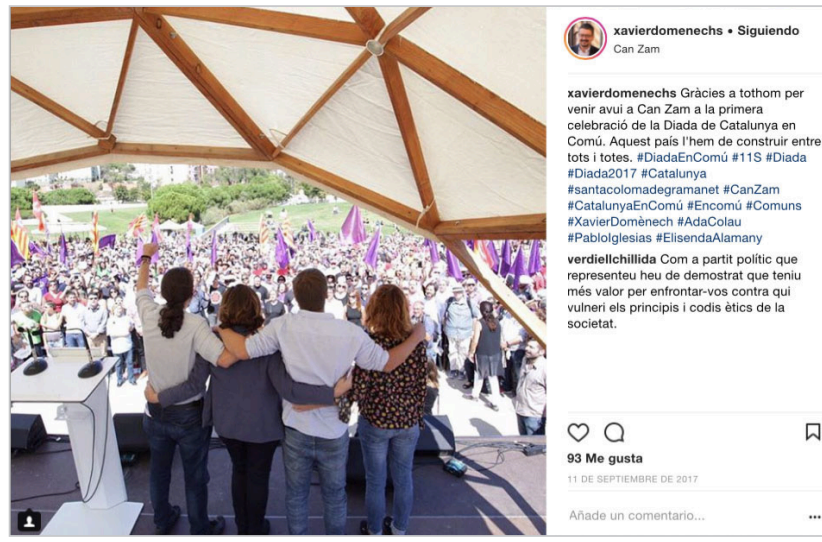

Imagen 15. "Espacio público"
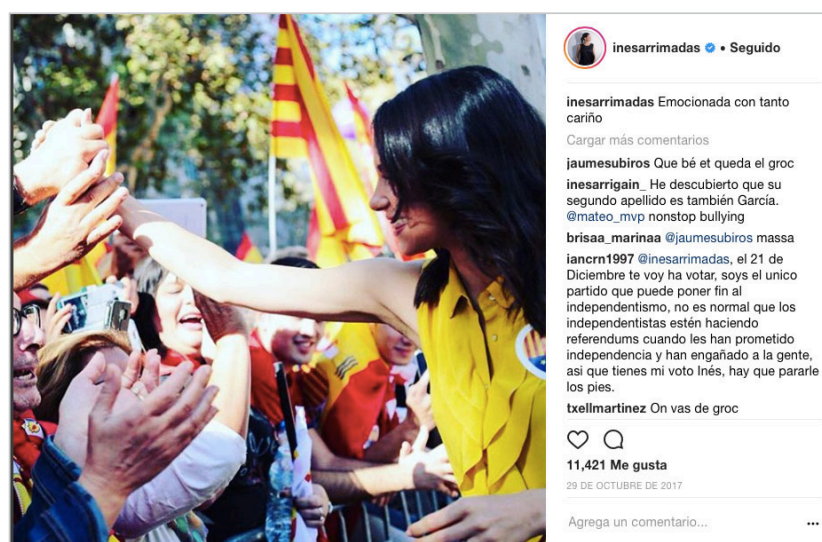

Imagen 16. "Espontaneidad estratégica" 

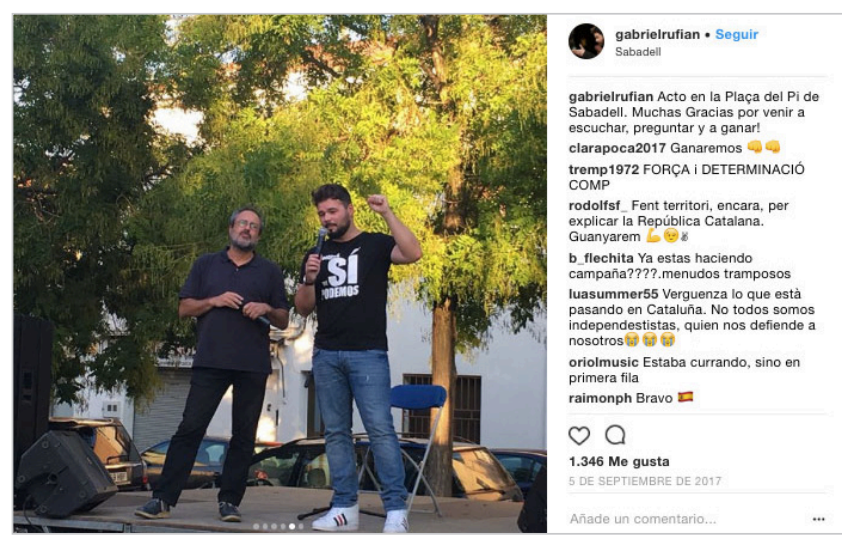

Imagen 17. Puesta en escena "Amateur"

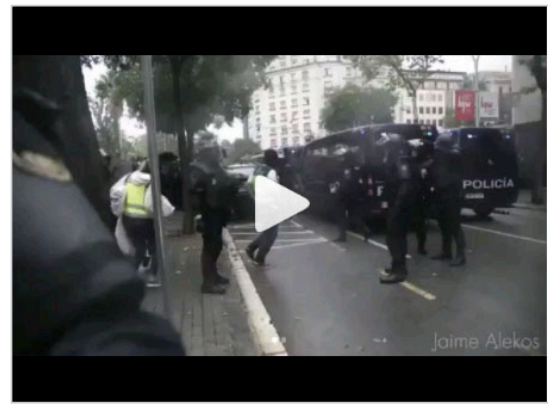

carlespuigdemont Avui demostrarem
de nou la forca d'tun poble irreductible.
Que ens guii sempre l'esperit de l't'10ct Cargar más comentarios maki_m___crac_øjoaquincusi pero mai albapm__. emmaa.sanchezz $\bigcirc \bigcirc$ 45.729 Me gusta ज़̈ade un comentario

Imagen 19. Formato "Video"
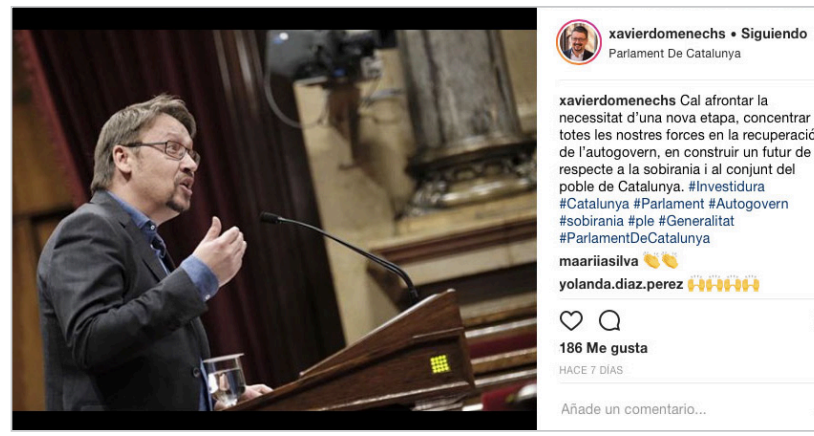
(9) xavierdomenechs Cal afrontar la
necessitat d'una nova etapa, concentra necessitat d'una nova etapa, concentrar
totes les nostres forces en la recuperacio de l'autogovern, en construir un futur de respecte a la sobirania ial conjunt de
poble de Catalunya. \#nvestidura poble de Catalunya. \#lnvestidura
\#Catalunya \#Parlament \#Autogover \#sobirania \#ple \#Generalita "ParlamentDeCatalunya maariasilva

\section{$\mathrm{OO}$} 186 Me gusta

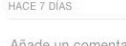

Imagen 20. Plano “Entero-medio"

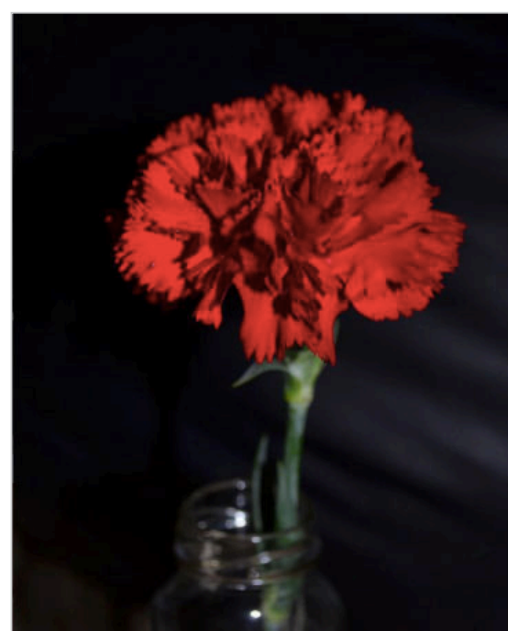

carlespuigdemont $\cdot$ Siguiendo

carlespuigdemont Demostrem una
vegada més el millor civisme al món vegada més el millor civisme al món
davant la política de la repressió i i bunquerització de l'Estat espanyol celins 31 Ben dit suandsuandsu No ens coneixen yomocract. yolsbch centro marcbenedicto @_cariza13 shhht sin rosas robadas lauraperezn Moltes felisitats atrasets Ordet @anabellope graciès primachet $\varnothing$. ninacuim Fsronlhe

$\mathrm{OO}$

25.037 Me gusta

3 DE OCTUARE DE 20
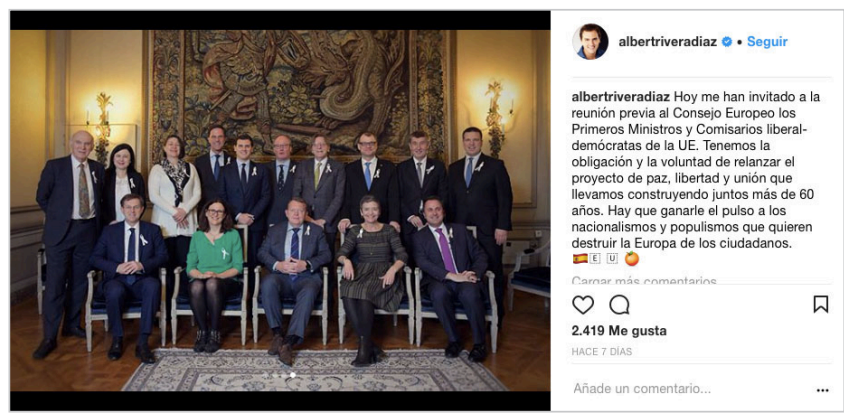

Imagen 18. Puesta en escena "Institucional"

como el "Institucional", que no encaja con el dinamismo de la plataforma, tiene una presencia muy limitada $(13,83 \%)$ (imagen 18).

\subsection{Cómo / Aspectos técnicos}

En la gestión técnica de la imagen destaca la apuesta mayoritaria por el formato fotográfico estándar (88,83\%). No obstante, en un contexto de crisis y movilización era de esperar una mayor presencia del vídeo que la detectada en la muestra (8,51\%) (imagen 19). Y, sobre todo, Ilama atención la ausencia de un formato de gran éxito y actualidad entre los usuarios de Instagram como es la selfie o la auto-foto espontánea (1,59\%). Este resultado es coherente con las funciones profesionales detectadas en el análisis y el contexto de grave crisis institucional analizado.

Respecto al patrón visual destaca un claro predominio de planos abiertos (85\%) que refuerzan el estilo informativo y profesional dominante en la muestra analizada. En concreto, los más habituales son el "General" $(37,23 \%)$ para representar eventos políticos y, sobre todo, el "Entero-medio" $(47,87 \%)$ con el que se (auto)presentan los políticos en muchas ocasiones (imagen 20). El "Primer plano" (8,51\%) o el plano "Detalle" $(6,38 \%)$ son reservados, casi en exclusiva, para objetos o elementos simbólicos (imagen 21), pero no para mostrar escenas personales.

En cuanto a la angulación de los planos, distinguimos que más de la mitad de la muestra utiliza el neutro o natural $(52,66 \%)$. Se trata de una perspectiva poco espectacular, pero que trasmite tranquilidad y estabilidad ya que está alineada con el punto de vista habitual de observación de la realidad. Por el contrario, sorprende el importante volumen de imágenes captadas con un ángulo "Picado" (26,60\%), asociado a situaciones de inferioridad o debilidad. Aunque normalmente el grado de angulación sea leve, no se considera lógica su utilización en un contexto de (auto)presentación positiva como el que ofrece Instagram. Por otra parte, como rasgo moderado de espectacularización sí que se detecta una presencia habitual de imágenes de ángulo "Contrapicado" (20,74\%) (imagen 22), muy eficaces para transmitir cualidades como la importancia o la superioridad $y$, sobre todo, para establecer una posición dominante del líder frente al observador.
Imagen 21. Plano "Detalle"

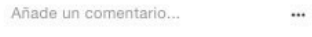

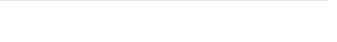


En términos generales, el tipo de iluminación habitual en la muestra es el natural o en "Clave media" (64,36\%). Este dato es coherente con el predominio de espacios públicos, pese a que ofrecen menos carga emocional que las fotos captadas con escasez o exceso de luz. Sin embargo, también se identifica un buen número de fotografías con una iluminación en "Clave baja" (25,53\%) (imagen 23). Este tipo de iluminación aporta una tonalidad a la fotografía muy atractiva para el espectador, asociada con frecuencia a la creación de ambientes de suspense.

En relación con los efectos de postproducción, un primer dato significativo es que casi la mitad de las fotografías $(41,49 \%)$ aparentemente no han sufrido ninguna alteración. Se trata de una tendencia hacia un estilo natural, derivado de un uso todavía limitado de la plataforma más que de una estrategia concreta. Sin embargo, el resto de la muestra sí ha sufrido algún tipo de retoque o edición antes de su publicación. Principalmente, galerías para presentar imágenes de forma secuencial $(35,64 \%)$, normalmente con un estilo convencional y poco atractivo. Sorprende el uso secundario de etiquetas $(10,6 \%)$ y rótulos $(10,6 \%)$, y no se detecta mayor uso de otros formatos de presentación como collages o mosaicos.

Respecto a los filtros, se advierte un uso limitado, cerca de un $10 \%$, pero significativo para aumentar su expresividad e impacto (imagen 24). Este tipo de efectos son uno de los mejores recursos de espectacularización que ofrece Instagram, ya que permite mejorar claramente y de forma sencilla el acabado de la imagen. Entre los filtros de mayor presencia en la muestra encontramos:

- los que saturan el color y añaden más contraste (Lo-Fi);

- los que aportan un aspecto antiguo a la fotografía y le dan mayor calidez (Earlybird);

- y los monocromo, que viran las imágenes a blanco y negro (Willow).

Finalmente, los resultados alcanzados sobre el tipo de apelación confirman una tendencia preferente hacia la emotividad (52\%) frente a la racionalidad $(37,77 \%)$ en el contexto de crisis política analizado. En el primer grupo encontramos imágenes en las que los líderes plantean una clara conexión
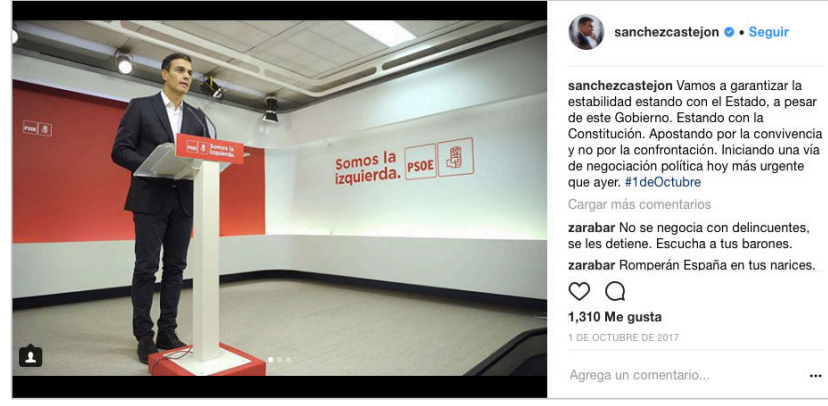

Imagen 22. Ángulo "Contrapicado"
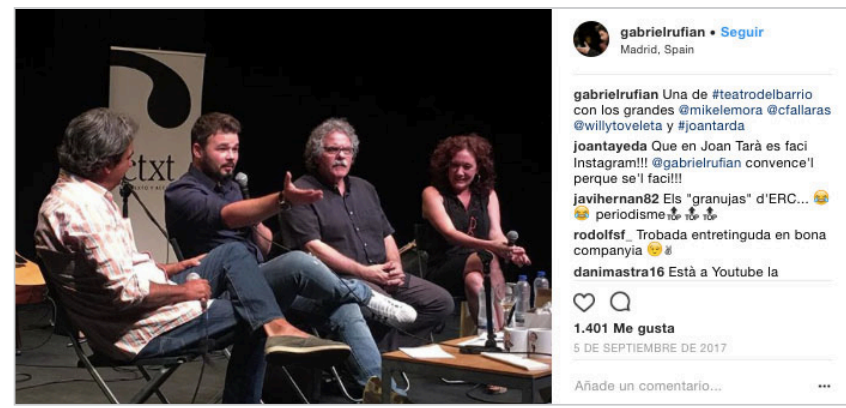

Imagen 23. Iluminación en "Clave baja"
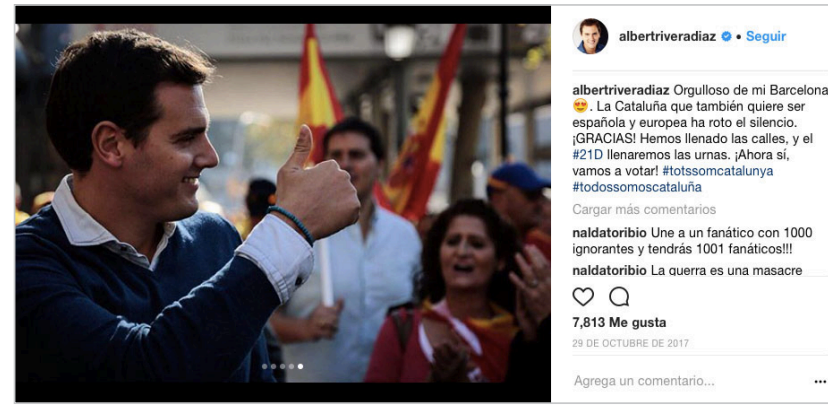

Imagen 24. Efecto "Filtro Lo-Fi"

emocional, normalmente positiva, con el espectador. Un buen ejemplo sería la apelación al orgullo por determinadas identidades políticas colectivas, a los afectos personales, o a la esperanza en un futuro mejor (imágenes 25 y 26 ].

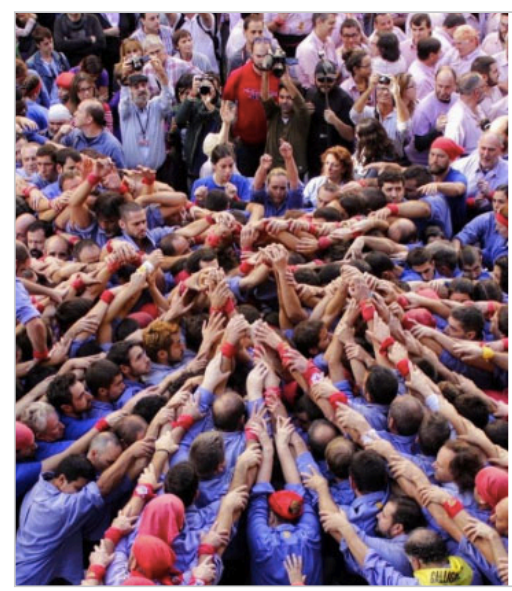

Imagen 25. Apelación "Emocional positiva"

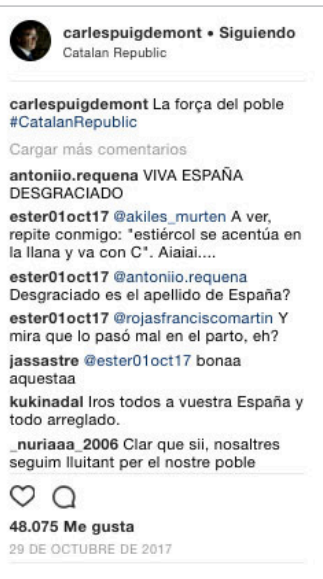

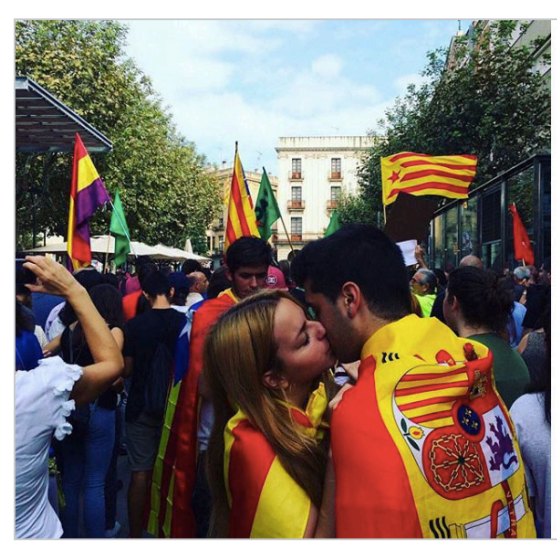

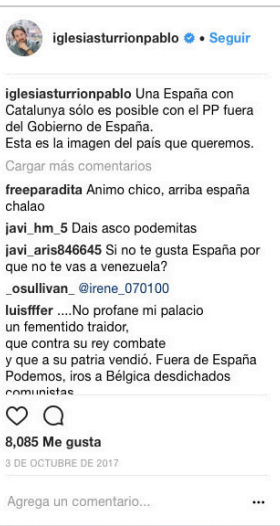

Imagen 26. Apelación “Emocional positiva” 
Por otro lado, la apelación racional interpela al espectador a partir del refuerzo de argumentos de carácter informativo, como, por ejemplo, los presentados en una rueda de prensa o un mensaje institucional (imagen 27). En ocasiones, para interpretar correctamente las apelaciones planteadas por la imagen es necesario analizar tanto la fotografía como el comentario textual adjunto.

\section{Conclusiones}

Los resultados exploratorios alcanzados dibujan un diagnóstico bastante completo sobre el grado de aprovechamiento actual de Instagram por parte de los políticos españoles. Globalmente, se constata que se encuentra todavía en una fase de experimentación en busca de sus funciones más eficaces y un estilo comunicativo definitivo. Si bien los líderes y los partidos han avanzado en la normalización de su uso político, todavía no presenta un patrón consolidado.

Esta etapa intermedia en su desarrollo se caracteriza por la progresiva ampliación de los registros y estilos comunicativos, desde una (auto)presentación básica de los líderes hacia una espectacularización más intensa. Dentro del caso del proceso independentista en Cataluña, son buenos ejemplos de esta evolución los líderes de Ciudadanos (Rivera y Arrimadas), los presidentes Puigdemont y Rajoy, y en menor medida Junqueras o el líder de Podemos, Iglesias. Pero, al mismo tiempo, también se detecta en muchos casos un uso todavía bastante limitado y convencional de la plataforma, como demuestran los casos de Sánchez, Iceta y Domènech.

La gestión política de Instagram se encuentra todavía en una fase de experimentación en busca de sus funciones más eficaces y un estilo comunicativo definitivo

Los resultados obtenidos sobre las $5 \mathrm{~W}$ visuales analizadas permiten identificar una serie de rasgos temáticos y expresivos espectaculares que pueden dinamizar en gran medida la gestión de Instagram, y resultan aplicables más allá del caso español:

- una intensa dinámica de personalización: por el momento Instagram ha servido como escaparate visual de los líderes para reforzar eficazmente roles profesionales clásicos de gran valor simbólico como el "comunicador" que dialoga y ofrece soluciones; "el hombre de estado" que encarna la legalidad o un nuevo orden político; o el "líder de masas" que afronta un conflicto identitario;

- el peso significativo que tiene la actualidad política: Instagram no rehúye los temas conflictivos ni su seguimiento en tiempo real por lo que, de cara al futuro, su valor movilizador potencial es claro;

- la orientación del mensaje: la apelación emocional positiva detectada es una vía potente para la espectacularización del mensaje político;

- la efectiva hibridación de espacios alcanzada ha logrado presentar conjuntamente tanto la actividad parlamentaria excepcional de estos meses como la representación del conflicto político en las calles;

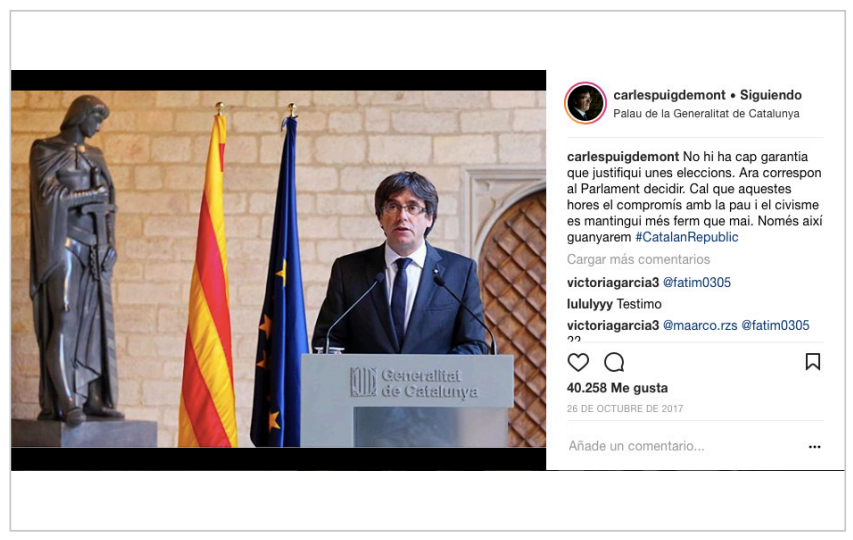

Imagen 27. Apelación "Racional"

- en cuanto a la técnica, los principales avances se han producido en la profesionalización de la puesta en escena con un estilo espontáneo y profesional, la experimentación con ciertos filtros, y el recurso a contrapicados y grandes planos generales.

Instagram se ha hecho sitio en la comunicación política. La fuerza de la imagen 2.0 ha encontrado en esta plataforma un canal prioritario de expresión

Por otro lado, es posible identificar importantes frenos a la innovación y la experimentación en el uso político de Instagram.

- el principal es sin duda la escasa humanización detectada: los líderes políticos no difunden imágenes relativas a su vida personal y familiar. Prescinden de contenidos potencialmente atractivos. Hay un desaprovechamiento transversal, tanto a nivel de agenda, como de presencia de actores, atributos y de representación de espacios;

- tampoco se utiliza eficazmente Instagram para implementar algunas funciones clásicas como movilizar al electorado o criticar al adversario. Además tampoco ha sido hasta el momento una plataforma propicia para el humor y el entretenimiento;

- conviene subrayar la presencia de tipos de puesta en escena problemáticos (amateur, posado o institucional), como una limitación evidente para un uso político profesional de la plataforma.

- a nivel técnico, la gran asignatura pendiente es la normalización del uso del vídeo y una gestión más estratégica de planos cortos, iluminación y selfies.

Instagram se ha hecho sitio en la comunicación política. La fuerza de la imagen 2.0 ha encontrado en esta plataforma un canal prioritario de expresión. Y su orientación hacia contenidos y estilos espectaculares en contextos de crisis parece decidida. Tras mostrar las luces y sombras en la gestión de los líderes, el siguiente paso es profundizar en el uso de los partidos de esta plataforma en busca de sinergias y un reparto coordinado de estrategias que potencie la movilización política. 


\section{Agradecimientos}

Este artículo se enmarca dentro de los resultados del proyecto de investigación UJI-B2017-55, financiado por la Universitat Jaume I de Castellón, dentro del Plan de Promoción de la Investigación (Convocatoria 2017).

\section{Referencias}

Adam, Silke; Maier, Michaela (2010). "Personalization of politics. A critical review and agenda for research". Annals of the International Communication Association, v. 34, n. 1, pp. 213-257.

https://doi.org/10.1080/23808985.2010.11679101

Balmas, Meital; Sheafer, Tamir (2013). "Leaders first, countries after: Mediated political personalization in the international arena". Journal of communication, v. 63, n. 3, pp. 454-475.

https://doi.org/10.1111/jcom.12027

Bardin, Laurence (2002). El análisis de contenido. Madrid: Akal. ISBN: 8476000936

Bentivegna, Sara (2015). A colpi di tweet: la politica in prima persona. Bologna: II Mulino. ISBN: 9788815257215

Berrocal-Gonzalo, Salomé; Redondo-García, Marta; Torres-Chico, Luis-Miguel (2015). "La crisis como espectáculo: el infoentretenimiento en las noticias sobre el rescate bancario en la prensa española de referencia". Communication \& society, v. 28, n. 4 , pp. 1-16.

https://doi.org/10.15581/003.28.4.sp.1-16

Casero-Ripollés, Andreu (2008). "Modelos de relación entre periodistas y políticos: la perspectiva de la negociación constante". Estudios sobre el mensaje periodístico, v. 14, pp. 111-128.

http://revistas.ucm.es/index.php/ESMP/article/view/ ESMP0808110111A

Casero-Ripollés, Andreu (2009). La construcción mediática de las crisis políticas. Madrid: Fragua. ISBN: 9788470742750

Casero-Ripollés, Andreu; Ortells-Badenes, Sara; Rosique-Cedillo, Gloria (2014). "La espectacularización de la política. Consecuencias democráticas de la disolución de las fronteras entre información, entretenimiento y privacidad en la era digital". Telos: Cuadernos de comunicación e innovación, n. 99, pp. 45-54.

http://hdl.handle.net/10234/127530

Casero-Ripollés, Andreu; Sintes-Olivella, Marçal; Franch, Pere (2017). "The populist political communication style in action: Podemos's issues and functions on Twitter during the 2016 Spanish general election". American behavioral scientist, v. 61, n. 9, pp. 986-1001.

http://hdl.handle.net/10234/173222

https://doi.org/10.1177/0002764217707624

Chadwick, Andrew (2013). The hybrid media system: Politics and power. Oxford University Press. ISBN: 0199759480

De-Aguilera, Miguel; Casero-Ripollés, Andreu (2018). “¿Tecnologías para la transformación? Los medios sociales ante el cambio político y social". Icono 14 , v. 16 , n. 1, pp. $1-21$. https://doi.org/10.7195/ri14.v16i1.1162

Ekman, Mattias; Widholm, Andreas (2017). "Political communication in an age of visual connectivity: Exploring Instagram practices among Swedish politicians". Northern lights: Film \& media studies yearbook, v. 15, n. 1, pp. 15-32. https://doi.org/10.1386/nl.15.1.15_1

Eldin, Amira K. (2016). "Instagram role in influencing youth opinion in 2015 election campaign in Bahrain". European scientific journal, v. 12, n. 2, pp. 245-257.

https://doi.org/10.19044/esj.2016.v12n2p245

Enli, Gunn (2017). "Twitter as arena for the authentic outsider: Exploring the social media campaigns of Trump and Clinton in the 2016 US presidential election". European journal of communication, v. 32, n. 1, pp. 50-61.

https://doi.org/10.1177/0267323116682802

Enli, Gunn; Skogerb $\emptyset$, Eli (2013). “Personalized campaigns in party-centred politics: Twitter and Facebook as arenas for political communication". Information, communication \& society, v. 16, n. 5, pp. 757-774.

https://doi.org/10.1080/1369118X.2013.782330

Filimonov, Kirill; Russmann, Uta; Svensson, Jakob (2016). "Picturing the party: Instagram and party campaigning in the 2014 Swedish elections". Social media + society, v. 2, n. 3, pp. 1-11.

https://doi.org/10.1177/2056305116662179

García-Beaudoux, Virginia; D’Adamo, Orlando (2006). “Comunicación política y campañas electorales. Análisis de una herramienta comunicacional: el spot televisivo". Polis: investigación y análisis sociopolítico y psicosocial, v. 2, n. 2, pp. 81-111.

http://www.redalyc.org/pdf/726/72620204.pdf

Gil-de-Zúñiga, Homero; Jung, Nakwon; Valenzuela, Sebastián (2012). "Social media use for news and individuals' social capital, civic engagement and political participation". Journal of computer-mediated communication, v. 17, n. 3, pp. 319-336.

https://doi.org/10.1111/j.1083-6101.2012.01574.x

Goodnow, Trischa (2013). "Facing off: A comparative analysis of Obama and Romney Facebook timeline photographs". American behavioral scientist, v. 57, n. 11, pp. 1584-1595. https://doi.org/10.1177/0002764213489013

IAB (2018). Estudio anual redes sociales 2017. Madrid: Interactive Advertising Bureau.

https://iabspain.es/wp-content/uploads/iab_ estudioredessociales_2017_vreducida.pdf

IAMC (2018). 20 Encuesta AIMC a usuarios de internet Navegantes en la Red. Madrid: Asociación para la Investigación de Medios de Comunicación.

http://www.aimc.es/otros-estudios-trabajos/navegantesla-red/infografia-resumen-20o-navegantes-la-red

Igartua, Juan-José (2006). Métodos cuantitativos de investigación en comunicación. Barcelona: Bosch. ISBN: 97884 97902717

Instagram (2017). "Instagram's 2017 year in review". Instagram-press.com, Nov. 29. 
https://instagram-press.com/blog/2017/11/29/instagrams2017-year-in-review

Iosifidis, Petros; Wheeler, Mark (2018). “Modern political communication and web 2.0 in representative democracies", Javnost - The public, v. 25, n. 1-2, pp. 110-118. https://doi.org/10.1080/13183222.2018.1418962

Jebril, Nael; Albaek, Erik; De-Vreese, Claes H. (2013). “Infotainment, cynicism and democracy: The effects of privatization vs personalization in the news". European journal of communication, v. 28, n. 2, pp. 105-121.

https://claesdevreese.files.wordpress.com/2015/08/jebrilalbaek-devreese_2013.pdf

https://doi.org/10.1177/0267323112468683

Lalancette, Mireille; Raynauld, Vincent (2017). "The power of political image: Justin Trudeau, Instagram, and celebrity politics". American behavioral scientist. Online First. https://doi.org/10.1177/0002764217744838

Larsson, Anders-Olof (2016). “Online, all the time? A quantitative assessment of the permanent campaign on Facebook". New media \& society, v. 18, n. 2, pp. 274-292. https://doi.org/10.1177/1461444814538798

Lilleker, Darren G.; Tenscher, Jens; Štětka, Václav (2015). "Towards hypermedia campaigning? Perceptions of new media's importance for campaigning by party strategists in comparative perspective". Information, communication \& society, v. 18, n. 7, pp. 747-765.

https://goo.gl/wVVnC6

https://doi.org/10.1080/1369118X.2014.993679

Loader, Brian D.; Vromen, Ariadne; Xenos, Michael A. (2016). "Performing for the young networked citizen? Celebrity politics, social networking and the political engagement of young people". Media, culture \& society, v. 38, n. 3, pp. 400-419.

https://doi.org/10.1177/0163443715608261

López-García, Guillermo (2017). “Comunicación política y discursos sobre el poder". El profesional de la información, v. 26 , n. 4 , pp. 573-578.

https://doi.org/10.3145/epi.2017.jul.01

López-Meri, Amparo; Marcos-García, Silvia; Casero-Ripollés, Andreu (2017). What do politicians do on Twitter? Functions and communication strategies in the Spanish electoral campaign of 2016". El profesional de la información, v. 26, n. 5, pp. 795-804.

https://doi.org/10.3145/epi.2017.sep.02

López-Rabadán, Pablo; López-Meri, Amparo; Doménech-Fabregat, Hugo (2016). "La imagen política en Twitter. Usos y estrategias de los partidos políticos españoles". Index. Comunicación, v. 6, n. 1, 165-195.

http://hdl.handle.net/10234/165146

Marcos-García, Silvia; Alonso-Muñoz, Laura (2017). "La gestión de la imagen en campaña electoral. El uso de Instagram por parte de los partidos y líderes españoles en el 26J". En: Sierra-Sánchez, Javier; Liberal-Ormaechea, Sheila (coords.). Uso y aplicación de las redes sociales en el mundo audiovisual y publicitario. Madrid: McGraw-Hill, pp. 107118. ISBN: 9788448613570
Marland, Alex (2012). "Political photography, journalism, and framing in the digital age: The management of visual media by the Prime Minister of Canada". The international journal of press/politics, v. 17, n. 2, pp. 214-233. https://doi.org/10.1177/1940161211433838

McGregor, Shannon C.; Lawrence, Regina G.; Cardona, Arielle (2017). "Personalization, gender, and social media: gubernatorial candidates' social media strategies". Information, communication \& society, v. 20, n. 2, pp. 264-283. https://doi.org/10.1080/1369118X.2016.1167228

Meilán, Xabier (2010). Causas y consecuencias del consumo de información política en España (2000-2009). Madrid: CIS. ISBN: 9788474765212

https://libreria.cis.es/static/pdf/OyA68a_1.pdf

Meyen, Michael; Thieroff, Markus; Strenger, Steffi (2014). "Mass media logic and the mediatization of politics: a theoretical framework". Journalism studies, v. 15, n. 3, pp. 271288.

https://doi.org/10.1080/1461670X.2014.889459

Montagut, Marta; Carrillo, Nereida (2017). “Estrategias de espectacularización en las tertulias políticas televisivas. Caso de la cobertura de las elecciones municipales de Barcelona de 2015". El profesional de la información, v. 26, n. 4, pp. 621-629.

https://doi.org/10.3145/epi.2017.jul.06

Muñoz, Caroline-Lego; Towner, Terri L. (2017). "The image is the message: Instagram marketing and the 2016 presidential primary season". Journal of political marketing, v. 16, n. 3-4, pp. 290-318.

https://doi.org/10.1080/15377857.2017.1334254

Oliva, Mercè; Pérez-Latorre, Óliver; Besalú, Reinald (2015). "Celebrificación del candidato. Cultura de la fama, marketing electoral y construcción de la imagen pública del político". Arbor, v. 191, n. 775, a270. https://doi.org/10.3989/arbor.2015.775n5009

Pellisser-Rossell, Nel·lo; Pineda, Antonio (2014). “Información política televisiva y espectacularización: un análisis comparativo de programas informativos y de infoentretenimiento". Estudios sobre el mensaje periodístico, v. 20, n. 2, pp. 821-839.

http://hdl.handle.net/11441/61334

Powell, Thomas E.; Boomgaarden, Hajo G.; De-Swert, Knut; De-Vreese, Claes H. (2015). "A clearer picture: The contribution of visuals and text to framing effects". Journal of communication, v. 65, n. 6, pp. 997-1017.

https://doi.org/10.1111/jcom.12184

Quevedo-Redondo, Raquel; Portalés-Oliva, Marta (2017). "Imagen y comunicación política en Instagram. Celebrificación de los candidatos a la presidencia del Gobierno". El profesional de la información, v. 26, n. 5, pp. 916-927.

https://doi.org/10.3145/epi.2017.sep.13

Quevedo-Redondo, Raquel; Portalés-Oliva, Marta; Berrocal-Gonzalo, Salomé (2016). "El uso de la imagen en Twitter durante la campaña electoral municipal de 2015 en España". Revista latina de comunicación social, v. 71, pp. 85-107. https://doi.org/10.4185/RLCS-2016-1085 
Sartori, Giovanni (1998). Homo videns: la sociedad teledirigida. Madrid: Taurus. ISBN: 8430602739

http://centromemoria.gov.co/wp-content/uploads/2013/11/ Homo_Videns_La_sociedad_teledirigida.pdf

Schill, Dan (2012). "The visual image and the political image: A review of visual communication research in the field of political communication". Review of communication, v. 12 , n. 2, pp. 118-142.

https://doi.org/10.1080/15358593.2011.653504

Selva-Ruiz, David; Caro-Castaño, Lucía (2017). "Uso de Instagram como medio de comunicación política por parte de los diputados españoles: la estrategia de humanización en la 'vieja' y la 'nueva' política". El profesional de la información, v. 26, n. 5, pp. 903-915.

https://doi.org/10.3145/epi.2017.sep.12

Strömbäck, Jesper (2008). "Four phases of mediatization: An analysis of the mediatization of politics". The international journal of press/politics, v. 13, n. 3, pp. 228-246.

https://doi.org/10.1177/1940161208319097

Strömbäck, Jesper; Djerf-Pierre, Monika; Shehata, Adam (2013). "The dynamics of political interest and news me- dia consumption: A longitudinal perspective". International journal of public opinion research, v. 25, n. 4, pp. 414-435. https://doi.org/10.1093/ijpor/eds018

Stromer-Galley, Jennifer (2014). Presidential campaigning in the internet age. Oxford University Press. ISBN: 9780 199731947

Towner, Terri L.; Muñoz, Caroline-Lego (2017). “Picture perfect? The role of Instagram in issue agenda setting during the 2016 presidential primary campaign". Social science computer review, v. 36, n. 4, pp. 484-499.

https://doi.org/10.1177/0894439317728222

Van-Aelst, Peter; Sheafer, Tamir; Stanyer, James (2012). "The personalization of mediated political communication: A review of concepts, operationalizations and key findings". Journalism, v. 13, n. 2, pp. 1-18.

https://doi.org/10.1177/1464884911427802

WeAreSocial (2018). "Special reports. Digital in 2018: World's internet users pass the 4 billion mark". Wearesocial. com, January $30^{\text {th }}$.

https://wearesocial.com/blog/2018/01/global-digitalreport-2018

\section{Colección de libros de bolsillo El profesional de la información (Editorial UOC) Últimos títulos publicados}
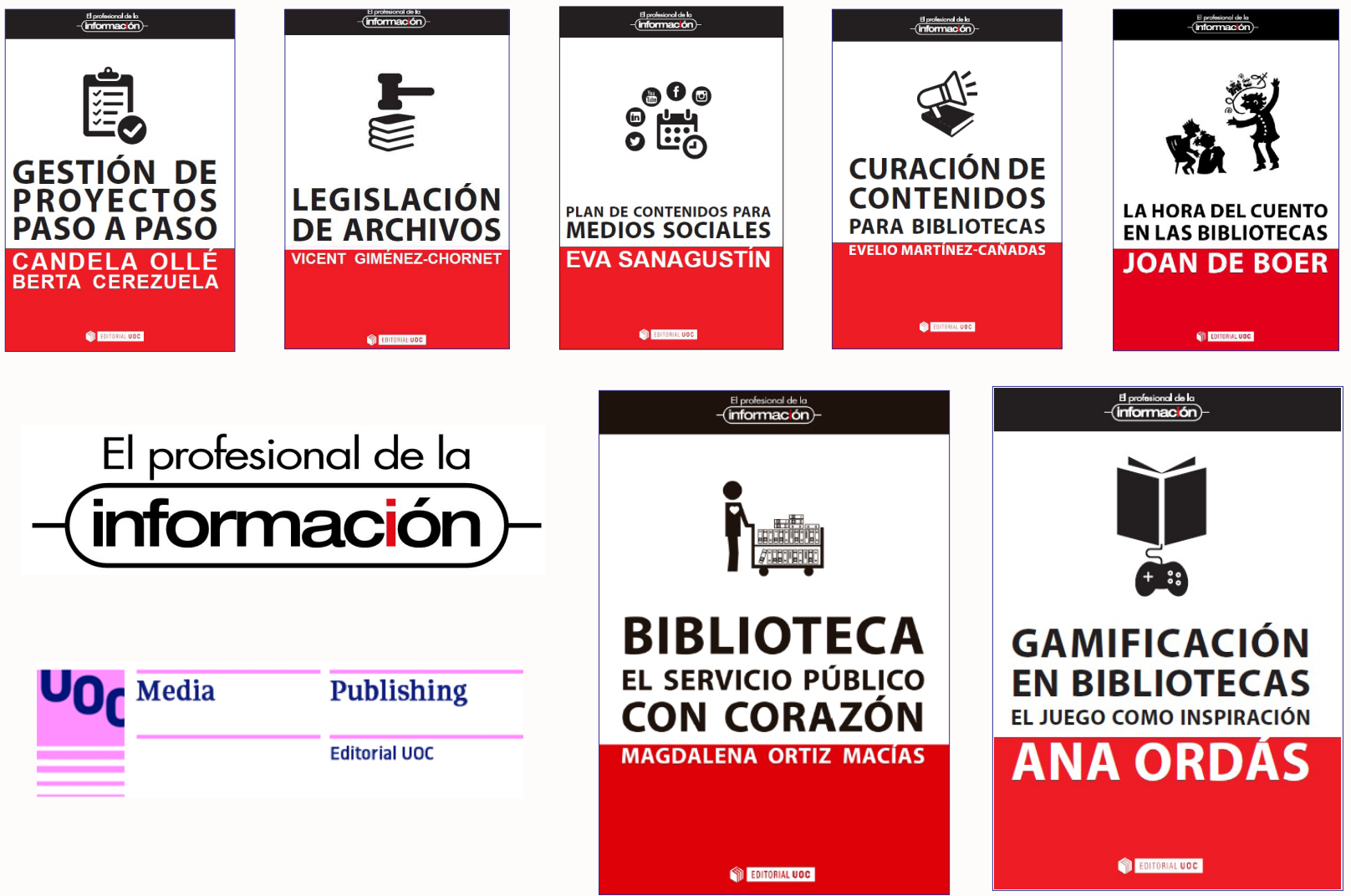

Más información:

http://www.elprofesionaldelainformacion.com/libros.html 